\title{
Technical Comparison of Candidate Ion Exchange Media for Small Column Ion Exchange (SCIX) Applications in Support of Supplemental LAW Pretreatment
}

\section{Prepared by}

A. A. Ramsey, AEM Consulting. LLC

M. R. Thorson, Washington River Protection Solutions, LLC

Richland, Washington 99352

U.S. Department of Energy Contract DE-AC27-08RV14800

\author{
EDT/ECN: DRF UC: \\ Cost Center: Charge Code: \\ B\&R Code: $\quad$ Total Pages: 45
}

Key Words: Spherical resorcinol formaldehyde, ion exchange, supplemental pretreatment, low activity waste

Abstract: At-tank supplemental pretreatment including both filtration and small column ion exchange is currently under evaluation to facilitate salt waste retrieval and processing in the Hanford tank farms. Spherical resorcinol formaldehyde (sRF) resin is the baseline ion exchange resin for use in the Waste Treatment and Immobilization Plant (WTP). This document provides background and technical rationale to assist in determining whether spherical resorcinol formaldehyde (SRF) is also the appropriate ion exchange resin for supplemental LAW pretreatment processes and compares SRF with crystalline silicotitanate (CST) as potential supplemental pretreatment ion exchange media.

TRADEMARK DISCLAIMER. Reference herein to any specific commercial product, process, or service by trade name, trademark, manufacturer, or otherwise, does not necessarily constitute or imply its endorsement, recommendation, or favoring by the United States Government or any agency thereof or its contractors or subcontractors.

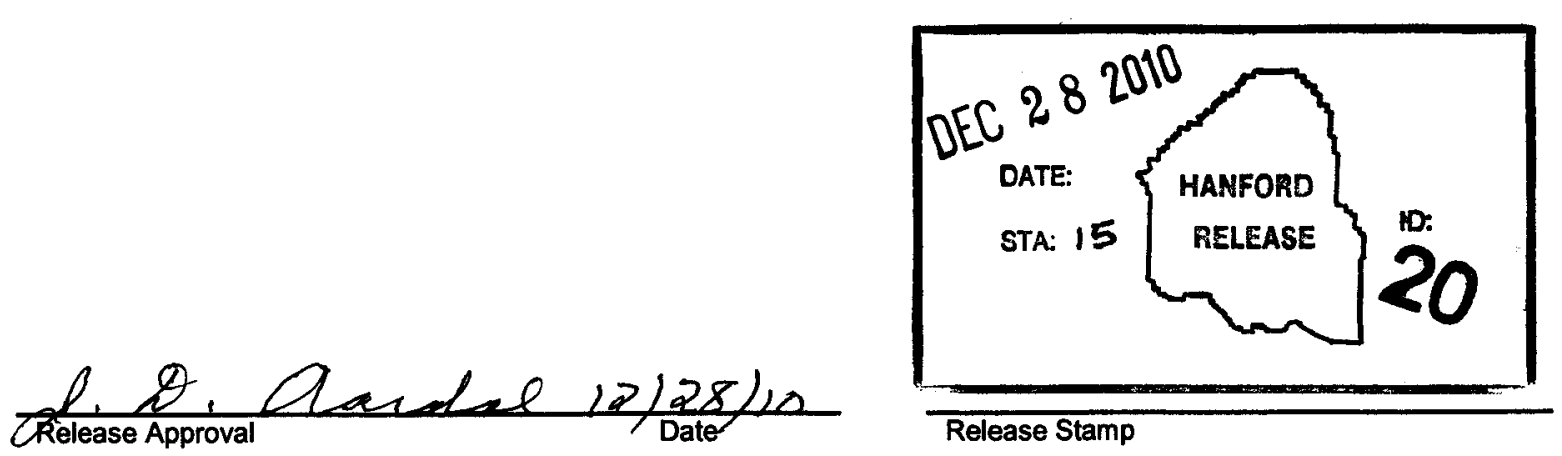




\title{
Technical Comparison of Candidate Ion Exchange Media for Small Column Ion Exchange (SCIX) Applications in Support of Supplemental LAW Pretreatment
}

\author{
A. A. Ramsey \\ AEM Consulting, LLC \\ M. R. Thorson \\ Washington River Protection Solutions LLC
}

December 2010

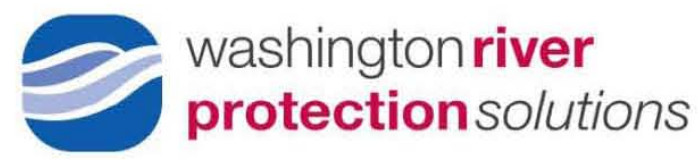

Post Office Box 850

Richland, Washington

Prepared for the U.S. Department of Energy

Office of River Protection

Contract No. DE-AC27-08RV14800 


\section{EXECUTIVE SUMMARY}

The Hanford Site was the world's first plutonium production complex. The legacy of 40 years of plutonium production includes approximately 57 million gallons of radioactive and chemically hazardous waste byproducts. These wastes are stored onsite primarily in 177 underground storage tanks. Protecting the adjacent Columbia River from contamination, while performing environmental cleanup, is the Hanford Site's primary mission.

The cleanup strategy is to safely empty and decommission the underground storage tanks and stabilize the wastes into suitable waste forms. Vitrification has been identified as the primary processing technology for Hanford tank waste (24590-WTP-RPT-PT-02-005, Rev. 5, Flowsheet Bases, Assumptions and Requirements). Prior to vitrification, the wastes must be separated into high level waste (HLW) and low activity waste (LAW) streams compatible with production limitations and regulatory requirements. Preparing the LAW stream includes removing insoluble solids and cesium-137 $\left({ }^{137} \mathrm{Cs}\right)$ from the tank waste supernatant by filtration and ion exchange.

Modeling of the Waste Immobilization and Treatment Plant (WTP) complex, currently under construction, shows that the as-designed processing capability of the WTP will fall short of the desired throughput unless supplemental treatment options can be implemented to augment operations (ORP-11242, River Protection Project System Plan, Rev. 5). In particular, the pretreatment facility that prepares waste feed for the WTP is not sized to process the LAW quantities anticipated within the desired time schedule. Supplemental pretreatment options are under investigation that potentially could relieve the WTP of much of the LAW inventory. Diverting some of this burden from the WTP is particularly important as the LAW production rate potentially impacts the immobilized HLW production rate as well.

Small Column Ion Exchange (SCIX) would be a key component of the proposed supplemental LAW pretreatment. SCIX, preceded by filtration, could be deployed at-tank. The resulting pretreated LAW could be processed through WTP LAW vitrification or by an alternate waste processing facility. Spherical Resorcinol Formaldehyde (sRF) is the baseline ion exchange resin for the WTP pretreatment facility (24590-WTP-DB-ENG-01-001, Rev 1O, Basis of Design; 08WTP-096, Contract No. DE-AC27-01RVI4136-Recommendation for use of Spherical Resorcinol Formaldehyde $(R F)$ Resin as the Primary Cesium Ion Exchange Resin in the Waste Treatment and Immobilization Plant (WTP)). Though a decision has not been formalized, it is also the likely material choice for SCIX resin. The Savannah River Site (SRS) is also planning SCIX operations. The IX media it has selected is crystalline silicotitanate (CST). CST is a single-use media. As such, the spent CST becomes HLW. This document provides technical rationale to assist in selecting $\mathrm{SRF}$ for Hanford Site SCIX operations. This rationale may be summarized as follows:

- $\quad$ sRF has been selected as the ion exchange (IX) resin for pretreatment of LAW at WTP, and has undergone extensive, Hanford-specific waste simulant and actual waste testing.

- $\quad$ SRF has lower risk factors than CST, e.g. no observed risk of agglomeration and less risk of defeating WTP Cs removal in downstream processing steps.

- $\quad$ SRF has more tolerance for high temperature, which may enhance Hanford salt dissolution rates. 
- Because SRF is an elutable resin and can be disposed as LAW, it would not produce additional HLW solids as would a single use media (e.g. CST with an estimated 2 to $4 \%$ increase in total HLW glass).

- $\quad$ SRF resin material is less expensive than CST media.

- CST requires a mechanical grinding step, with a potential associated risk of insufficient size reduction, creating problems for DST recovery and WTP processing. 


\section{TABLE OF CONTENTS}

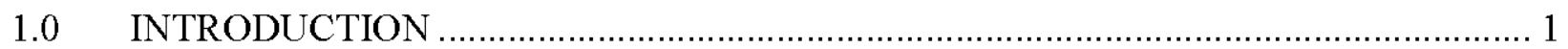

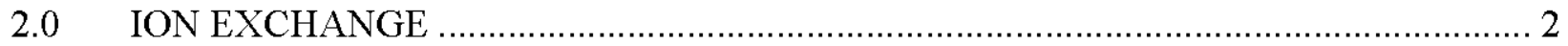

$2.1 \quad$ SPHERICAL RESORCINOL FORMALDEHYDE ........................................ 2

2.2 CRYSTALLINE SILICOTITANATE .............................................................. 4

2.3 HERSHELITE-BASED, CESIUM-SPECIFIC ION EXCHANGE MEDIA ......... 8

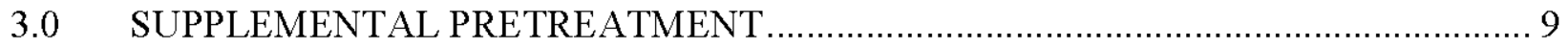

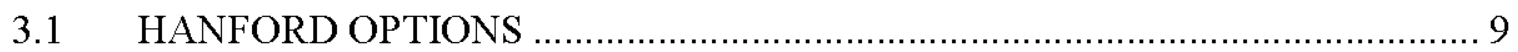

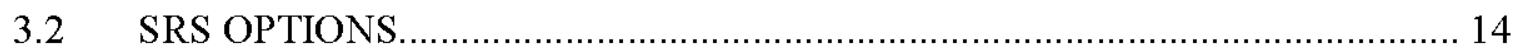

3.3 COMPARISON OF SRF AND CST FOR HANFORD SCIX APPLICATIONS 15

3.4 SPHERICAL RESORCINOL FORMALDEHYDE MATERIAL PRPERTIES . 18

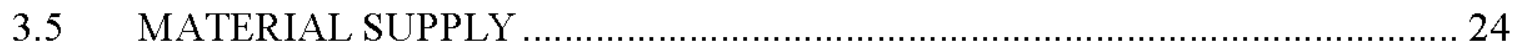

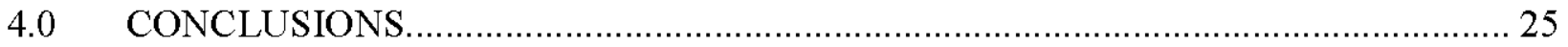

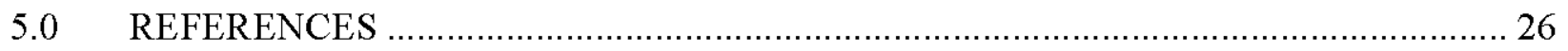

TABLE OF APPENDICES

APPENDIX A - HANFORD SITE SPECIFIC INFORMATION REGARDING ION EXCHANGE MEDIA SELECTION ……………………………………………...... A-1 APPENDIX B - SAVANNAH RIVER SITE SPECIFIC INFORMATION REGARDING ION EXCHANGE MEDIA SELECTION ............................................................................ B-1 APPENDIX C - TECHNICAL DATASHEETS FOR DYNOSEEDS ${ }^{\circledR}$ RF 380 and IONSIV ${ }^{\circledR}$

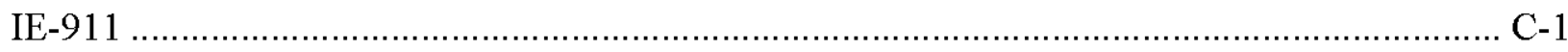

\section{TABLE OF FIGURES}

Figure 1. Micrograph of Spherical Resorcinol Formaldehyde. ................................................. 4

Figure 2. Micrograph of Crystalline Silicotitanate ............................................................... 5

Figure 3. SRS Small Column Ion Exchange Grinding Module for CST Media (ORNL design).. 7

Figure 4. Conceptual At-Tank Deployment of LAW Supplemental Pretreatment...................... 10

Figure 5. Pre-conceptual Engineering Design for Neutralizing sRF Acid Eluants. .................... 20

Figure 6. Resin Load Volume as a Function of Cycle for Representative Hanford Wastes........ 22

\section{TABLE OF TABLES}

Table 1. Comparison of sRF Resin for Hanford vs. CST media for SRS. 16

Table 2. Restoration Steps and Time for a 37" Diameter, 300-Gallon Bed of SCIX sRF Resin Using Recommended Flow Rates and Minimum Elution Volumes. 


\section{LIST OF TERMS}

\begin{tabular}{|c|c|}
\hline \multicolumn{2}{|c|}{ Abbreviations and Acronyms } \\
\hline CST & Crystalline silicotitanate \\
\hline CSSX & Caustic Side Solvent Extraction \\
\hline CXP & Cesium ion exchange process \\
\hline DOE & Department of Energy \\
\hline DSS & Decontaminated salt solution \\
\hline DST & Double shell tank \\
\hline DWPF & Defense Waste Processing Facility \\
\hline EM & Environmental Management \\
\hline EPRR & Enhanced Process for Radionuclide Removal \\
\hline FBSR & Fluidized Bed Steam Reformer \\
\hline HLW & High level waste \\
\hline IDF & Integrated Disposal Facility \\
\hline ILAW & Immobilized low activity waste \\
\hline IX & Ion exchange \\
\hline LAW & Low activity waste \\
\hline MSP & Modular salt processing \\
\hline ORNL & Oak Ridge National Laboratory \\
\hline ORP & Office of River Protection \\
\hline RCRA & Resource Conservation and Recovery Act \\
\hline $\mathrm{RMF}$ & Rotary microfiltration \\
\hline SCIX & Small column ion exchange \\
\hline SDF & Saltstone disposal facility \\
\hline SPF & Saltstone production facility \\
\hline sRF & spherical resorcinol formaldehyde \\
\hline SRNL & Savannah River National Laboratory \\
\hline SRS & Savannah River Site \\
\hline SST & Single shell tank \\
\hline $\mathrm{TF}$ & Tank Farm \\
\hline TRL & Technology readiness level \\
\hline WAC & Waste acceptance criteria \\
\hline WDOE & Washington Department of Ecology \\
\hline WTP & Waste Treatment and Immobilization Plant \\
\hline
\end{tabular}




$\begin{array}{ll}\text { Units } & \\ { }^{\circ} \mathrm{C} & \text { degrees Celcius } \\ \mathrm{Ci} / \text { liter } & \text { Curies per liter } \\ \mathrm{cfm} & \text { cubic feet per minute } \\ { }^{\circ} \mathrm{F} & \text { degrees Fahrenheit } \\ \mathrm{g} / \mathrm{cc} & \text { grams per cubic centimeter } \\ \mathrm{gpm} & \text { gallons per minute } \\ \mathrm{in} . & \text { inch } \\ \mathrm{M} & \text { molar }(1 \text { mole of solute per liter of solution) } \\ \mathrm{meq} / \mathrm{g} & \text { milli-equivalents per gram } \\ \mathrm{mmol} / \mathrm{g} & \text { milli-moles per gram } \\ \mathrm{Mrad} & \text { million radiation absorbed dose } \\ \mu \mathrm{m} & \text { micron or micrometer } \\ \mathrm{nCi} / \mathrm{g} & \text { nano-Curies per gram } \\ {[\quad]} & \text { chemical concentration }\end{array}$




\subsection{INTRODUCTION}

The purpose of this document is to provide technical background to support selection of an ion exchange media for Hanford at-tank small column ion exchange (SCIX) applications. As yet, a formal decision has not been made regarding the ion exchange (IX) media selection for the SCIX process. However, this document is intended to provide an overview of the options and enabling assumptions to guide that decision. Two primary materials are potential candidates for SCIX media:

- spherical resorcinol formaldehyde (sRF) resin, and

- crystalline silicotitanate (CST).

sRF is the IX resin that has been selected by the Hanford Waste Treatment and Immobilization Plant (WTP) for the Cs removal step in the pretreatment facility (24590-WTP-DB-ENG-01-001, Rev $1 O$ and 24590-WTP-RPT-RT-07-005, Rev 0). It is an organic, elutable, regenerable, multiuse ion exchange resin that does not generate additional high-level waste (HLW) solids. The WTP is currently being constructed and is scheduled to begin routine operations in December 2019 (ORP-11242). As sRF is the IX resin selected for WTP pretreatment, a great deal of Hanford-specific material characterization and performance data exists for this resin. Significant resources have already been spent investigating the use of sRF for Cs-removal for Hanford wastes. In addition, the spent SRF resin beads may be disposed as low activity waste (LAW). The current WTP pretreatment disposition option for spent sRF beads is to sluice the sRF beads from the IX column, and dry and dispose of them in high integrity containers (HIC). If sRF were selected for SCIX, much of the Hanford-specific technology development would already be complete.

The Savannah River Site (SRS) plans to use crystalline silicotitanate (CST) IX media for its SCIX application. CST is an inorganic, single-use, non-elutable material. At SRS the CST will be ground and discharged to be processed later as part of the HLW stream to the Defense Waste Processing Facility (DWPF). As CST is an inorganic ion exchange IX media, it may be successfully processed in the DWPF melter. In addition, the SRS SCIX mission has a shorter duration, smaller scope and an operational final disposition path, i.e. DWPF. If Hanford also chose to use CST for SCIX, it would face about twice the volume of CST HLW solids than SRS and have no available disposition path for these solids until the WTP begins radioactive operations. 


\subsection{ION EXCHANGE}

Ion exchange is the exchange of equivalent ions between two or more ionized species located in different phases, at least one of which is an ion exchanger. The process takes place without the formation of chemical bonds. In the case of at-tank SCIX, the process will be facilitated using flow-through columns filled with ion exchange media that selectively absorb Cs ions in the presence of soluble alkali, high salt concentration feeds. Two IX columns, configured in leadlag orientation, will remove Cs from the feed. The first, or lead, column will remove most of the Cs fed through the system, while the second, or lag column, will remove the residual Cs not captured by the lead column. Gamma detection will be used to determine when elution or replacement of the IX media is warranted. After elution, the freshly regenerated column will become the new lag column. Deploying the systems at-tank will enable the use of existing infrastructure, shielding, ventilation and permitting, (albeit with modifications).

Hanford and SRS both plan to use SCIX for Cs removal. While the two sites have similar reasons for SCIX, they also have different parameters, limitations and goals driving their IX media selection. The WTP at Hanford will use sRF as the baseline cesium ion exchange process (CXP) for waste pretreatment. SRS has selected Caustic Side Solvent Extraction (CSSX) for its Salt Waste Processing Facility (SWPF) and CST IX media for its in-tank SCIX application. A discussion of the SRF and CST materials, and site-specific reasons for their use, follows. A new IX material, engineered Herschelite, is also briefly discussed.

\subsection{SPHERICAL RESORCINOL FORMALDEHYDE}

The sRF resin, as produced, is an insoluble matrix in the form of $380+/-40 \mu \mathrm{m}$ spherical beads. The beads are porous, with Cs trapping sites throughout their matrices. The beads on a dry hydrogen-form basis are $99 \%$ composed of resorcinol formaldehyde polymer and $0.6 \%$ composed of a lightly cross-linked polystyrene seed material interspersed throughout. The sRF bead manufacturing process is specialized to create uniform diameter spheres with high durability and high diffusivity to meet $\mathrm{Cs}$ removal and resin regeneration needs. The sRF resin beads are selectively engineered to have an affinity for $\mathrm{Cs}$, size uniformity, and good hydraulic behavior.

The $\mathrm{sRF}$ resin is a reusable material. Once the resin is fully loaded with $\mathrm{Cs}$ ions, it is eluted using a dilute nitric acid solution that strips the $\mathrm{Cs}$ ions from the ion exchange sites. The $\mathrm{sRF}$ beads are then regenerated with a caustic solution followed by polished LAW feed ${ }^{1}$ provided by the IX column still in service. The purpose of completing regeneration with polished LAW feed is to fully prepare the resin to resume operations by duplicating the feed composition (minus Cs) that it will process. The regeneration steps are performed in upflow mode rather than the downflow mode used in normal operations. As regeneration of the beads causes some swelling of the material, performing regeneration steps in upflow mode causes a liquid supported mechanical fluidization of the beads, which eliminates potential bead-to-bead pressure, and

\footnotetext{
${ }^{1}$ Polished feed is LAW waste feed that has undergone SCIX and has been "polished" of Cs.
} 
physically resets the material to mitigate the risk of selective channeling through the resin bed. When used to process tank waste, the $\mathrm{sRF}$ beads will expand to $460+/-50 \mu \mathrm{m}$. As the resin ages due to chemical degradation by reaction with the dissolved oxygen in the waste stream, it causes the polymer to further expand to its final diameter of about $490 \mu \mathrm{m}$.

Figure 1 is a micrograph of $\mathrm{sRF}$ ion exchange resin from the second 100-gallon scale production batch of prototypic resin. It was manufactured by Microbeads AS of Skedsmokorset, Norway. The sRF synthesis process is protected by patent and trade secret information and includes seed material synthesis, seed preparation, and final resorcinol formaldehyde polymerization. Seed volume is about $0.5 \%$ of final synthesis bead volume. One batch of seeds can produce many batches of beads sufficient for thousands of gallons of finished resin. Finished resin production of 100 gallons hydrogen-form (160 gallons sodium-form $)^{2}$ resin requires about four weeks to complete with two weeks utilizing a critical path, 1,300-gallon reactor. (As production demand increases, Microbeads is planning equipment changes to allow100 gallons of hydrogen-form resin production per week.) Synthesis has been demonstrated at 100-gallon scale at both Microbeads in Skedsmokorset, Norway and Boulder Scientific Company in Mead, Colorado. A long-term supply strategy meeting the WTP's full mission resin needs has been formulated and is documented in CCN 188891.

${ }^{2} \mathrm{SRF}$ resin that has been prepared to have $\mathrm{Cs}$ ion exchange sites available. 
Figure 1. Micrograph of Spherical Resorcinol Formaldehyde.

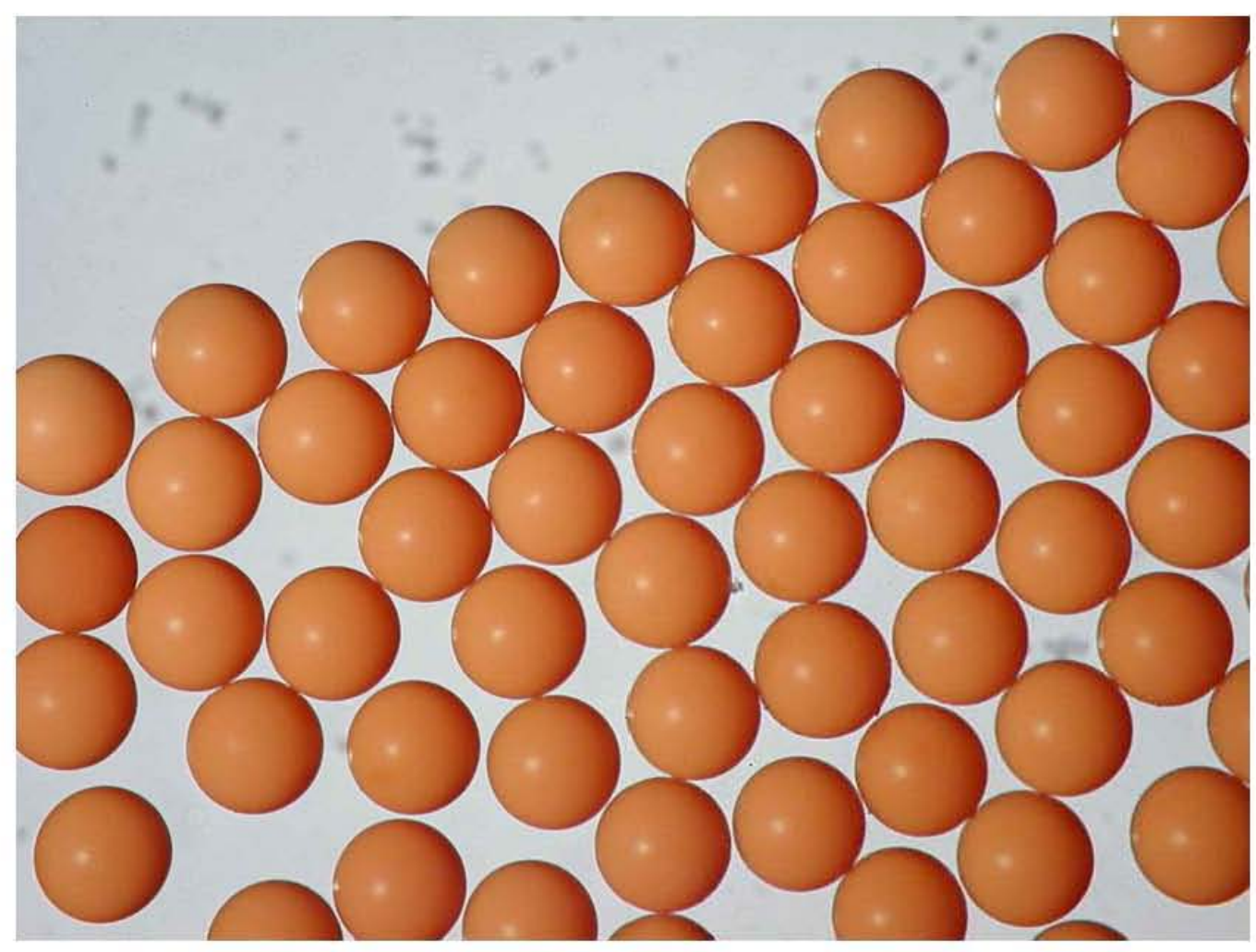

The WTP selected sRF resin as the baseline WTP Cs IX resin after six years of synthesis optimization and qualification testing (24590-WTP-RPT-07-005, Rev 0, 08-WTP-096, CCN 170573). Test and synthesis results accumulated during development of sRF for WTP pretreatment may be directly applied to the supplemental pretreatment option.

\subsection{CRYSTALLINE SILICOTITANATE}

SRS has multiple pathways for processing its salt waste. The SRS Z-Area Saltstone grouting facility began radioactive operations in 1990. SRS also plans to deploy a Salt Waste Production Facility that uses CSSX to separate LAW from HLW for further processing into saltstone. In addition, SRS has selected CST as the baseline Cs IX media for use in the SCIX In-Tank Modular Salt Processing (MSP) Mission. The CST was invented by Sandia National Laboratory and Texas A\&M University. It is manufactured as an engineered material by UOP (a Honeywell 
company) of Mount Laurel University with the trade name Ionsiv $\mathbb{R}^{3} \mathrm{IE}-911^{\mathrm{TM}}$. Figure 2 is a micrograph of the Ionsiv ${ }^{\circledR}$ IE-911 ${ }^{\text {TM }}$ CST material.

Figure 2. Micrograph of Crystalline Silicotitanate.

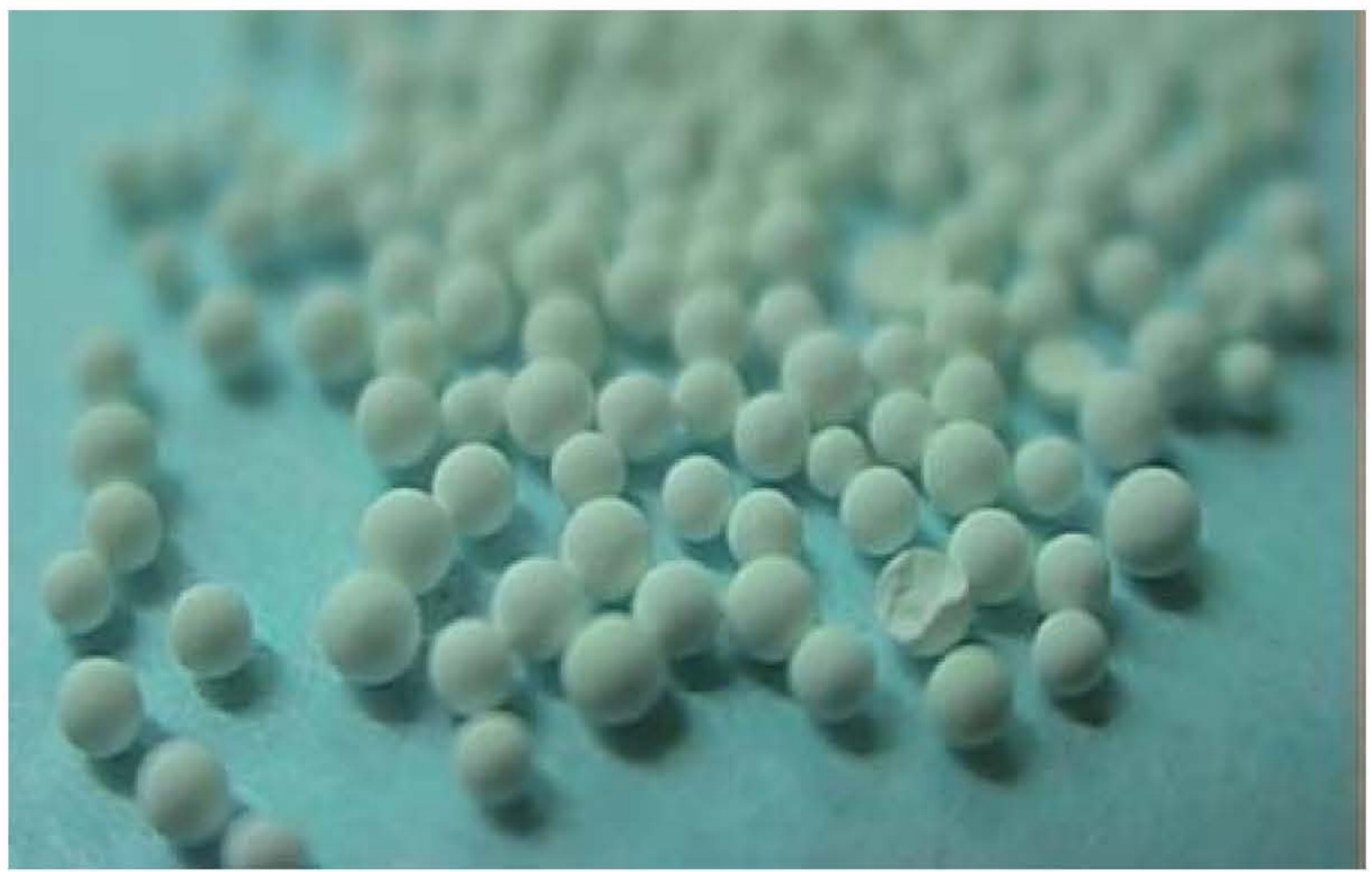

CST is not normally elutable, but does establish equilibrium with each associated feed. SRS performed a weighted systems engineering evaluation (G-ADS-H-00014) to determine the optimal ion exchange medium for its Enhanced Processes for Radionuclide Removal in support of its MSP Mission needs. The study evaluated multiple materials and configurations based on compatibility to downstream processes, operational complexity, technical maturity and schedule. Material options were narrowed down to CST and sRF. In fact, the engineering evaluation detailed in G-ADS-H-00014, down-selected to five viable options - four of those options included $\mathrm{SRF}$ as the ion exchange media in varying configurations.

Ultimately, CST was selected as the optimal resin for SRS salt wastes. This selection was largely based on the immediate need to deploy a system. CST was, at the time of the study, the more mature technology and the DWPF was already available as a disposition path for the spent media. The CST is a single use resin. SRS plans to use an in-tank SCIX system in lead-lag configuration. After the lead column is fully loaded with Cs, the CST material will be rinsed with caustic and water and then sluiced from the column in batches to a grinder module. The

${ }^{3}$ Ionsiv ${ }^{\circledR}$ IE-911 ${ }^{\mathrm{TM}}$ is a registered trademark of UOP, a Honeywell Company. 
material will then be mechanically ground for about 10 hours and sluiced back to SRS Tank 51 to be fed to the DWPF for processing. The SRS spent CST particle size requirements, after grinding, are that at least $98 \%$ of the CST is less than $38 \mu \mathrm{m}$ with a mean particle size between 5 and $20 \mu \mathrm{m}$ (SRR-SCIX-210-00026, 2010). The grinder module requires a separate riser. The SRS SCIX configuration will require a minimum of three large risers; one for each IX column and a third for the grinder assembly. Figure 3 is a diagram of the SRS SCIX grinder module.

The CST material is ground to make it more physically compatible with the overall rheology of the tank waste and meet DWPF sampler criteria (G-ADS-H-00014). After the spent CST is completely sluiced from the column ( $2+$ batches), ground, and discharged to the wash or direct feed tank, the column will be recharged with fresh CST. The fresh column will be placed in the lag mode and IX operations resumed. 
Figure 3. SRS Small Column Ion Exchange Grinding Module for CST Media (ORNL design).

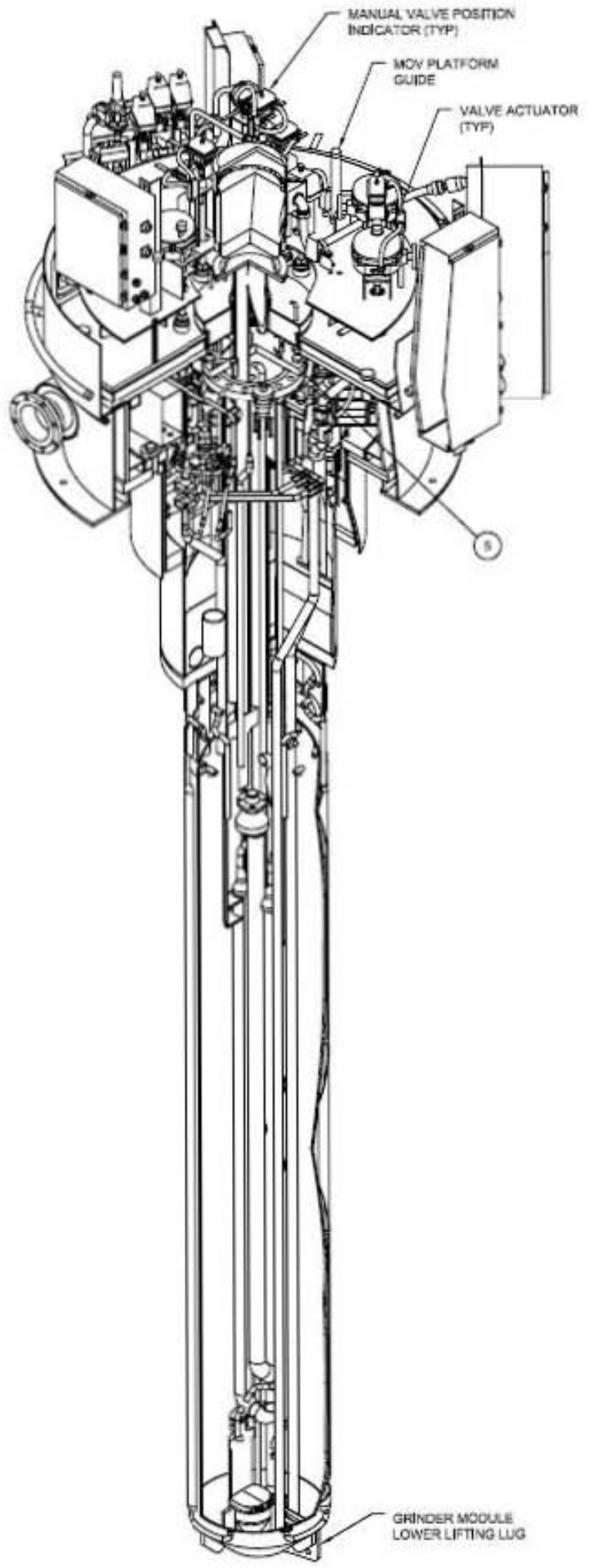

The engineering evaluation (G-ADS-H-00014) performed in 2008 recommended that $\mathrm{sRF}$ continue to be matured and evaluated for SRS applications. However, as SRS plans to deploy 
SCIX during early fiscal year (FY)14, it is pressing forward with CST for SCIX and does not plan to continue sRF development work for SRS applications. (SRR-LWP-2009-00001)

\subsection{HERSHELITE-BASED, CESIUM-SPECIFIC ION EXCHANGE MEDIA}

A new Cs-specific ion exchange media is being developed by Kurion, Inc. of Irvine, California. The material is a form of zeolite (alumino-silicate mineral) based on the Herschelite form. The exact chemistry of media is proprietary intellectual property. An engineered form of the material, that has a hydroxyapatite glass seed, is also being developed. This material is also a non-elutable media, but the base chemistry is compatible with glass forming and it has a lower bulk density than CST $(\approx 0.7 \mathrm{~g} / \mathrm{cc}$ versus $\approx 1.0 \mathrm{~g} / \mathrm{cc})$. $\mathrm{sRF}$ has a bulk density of $\approx 0.3 \mathrm{~g} / \mathrm{cc}$ in the hydrogen form.

Kurion, Inc. is proceeding with the Department of Energy (DOE) Technical Readiness Level (TRL) process to mature its products. However, the Kurion IX materials are still in the development stages and are not mature enough to directly compare to sRF and CST at this time. 


\subsection{SUPPLEMENT AL PRETREATMENT}

Supplemental pretreatment is a proposed method for providing extra waste pretreatment capability. Both the Hanford Site and SRS have plans to implement supplemental pretreatment to enhance mission schedule. The proposed plans are to deploy supplemental technology using existing equipment and infrastructure as a base platform. This strategy should expedite schedule and reduce costs, as baseline facilities and permitting are already in place.

\subsection{HANFORD OPTIONS}

Modeling of the WTP complex shows that the as-designed processing capability will fall short of the desired throughput unless supplemental treatment options can be implemented (ORP-11242, River Protection Project System Plan, Rev 4).

In addition, the WTP pretreatment facility as a function of equipment availability may limit WTP throughput and preclude meeting the desired schedule. To reduce this potential WTP throughput limitation, supplemental pretreatment options are under investigation that could offload much of the LAW feed from the WTP, thereby reducing or eliminating this throughput limitation.

Supplemental pretreatment of LAW is currently planned as a feed processing step for a supplemental LAW treatment system. This supplemental pretreatment strategy will be deployed at-tank and includes a filtration step (depicted as rotary microfilters in Figure 4) to remove entrained solids and provide clarified feed to the SCIX system. A conceptual illustration of this two-step pretreatment method is provided in Figure 4. 
Figure 4. Conceptual At-Tank Deployment of LAW Supplemental Pretreatment.

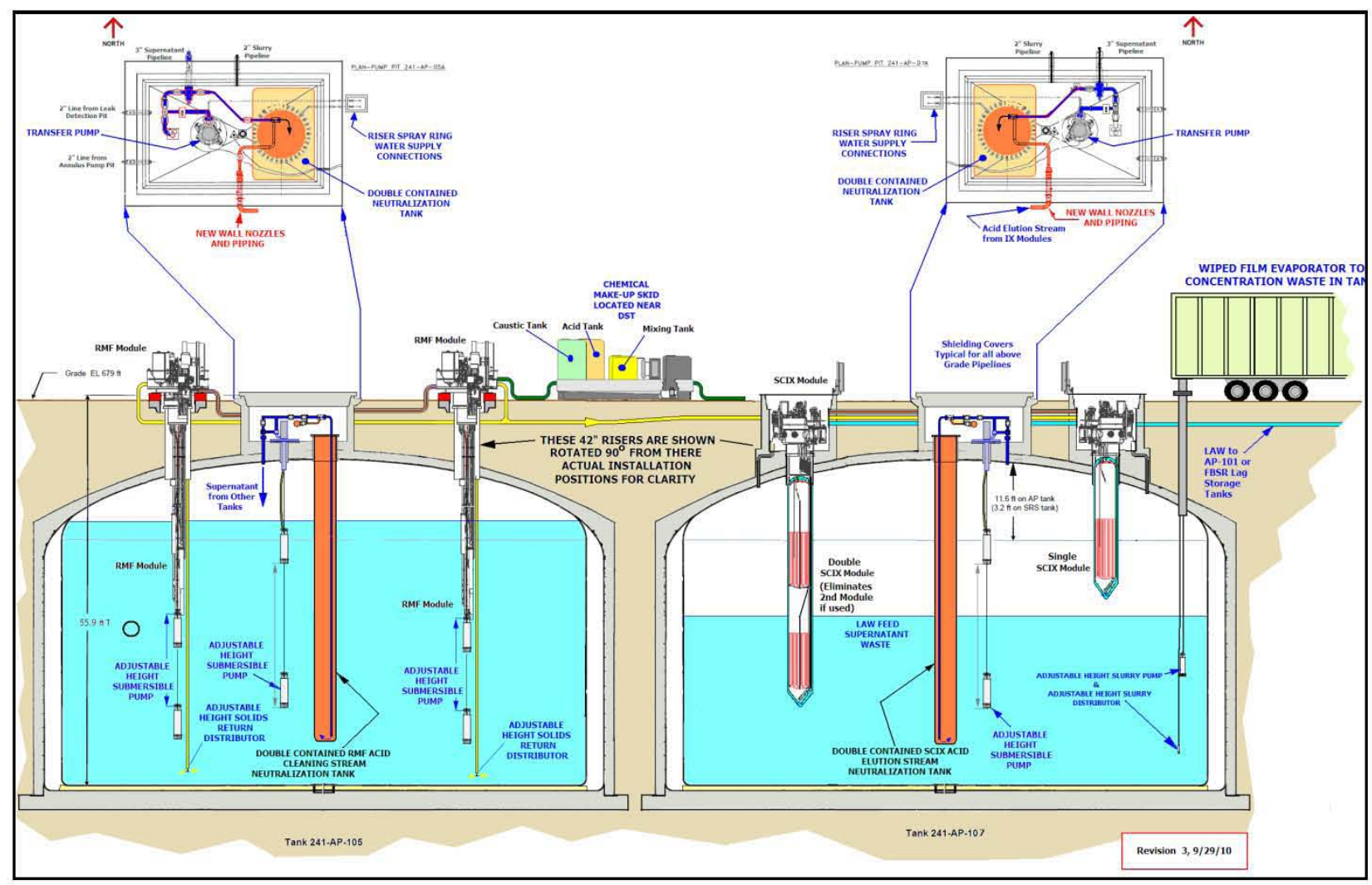

Figure 4 has been developed using the assumption that sRF resin will be material selected for the SCIX. This figure also depicts an acid stream neutralization vessel in the central DST riser (discussed further in Section 3.4 and Figure 5) and a conceptual IX column design (left column on Tank 241-AP-107) that enables both lead and lag columns to be housed within a single riser. It also assumes deployment in the 200 East Area AP tank farm and filtration performed in-riser using rotary microfilters. Because SRF resin is planned for IX of LAW at WTP pretreatment, using SRF resin for supplemental pretreatment applications would ensure consistency of LAW feed. With appropriate WTP to tank farm connecting piping, this strategy could enable early LAW start up, before WTP PT is available, and later potential cross-processing of supplemental LAW feed; i.e. tank farm supplemental feed could also be qualified for processing in the WTP LAW melter. While using sRF for at-tank SCIX is not the baseline strategy for WTP, it would provide versatility so that WTP LAW processing would have a qualified, complementary feed pretreatment train available should WTP pretreatment plant operations be interrupted. In addition, the same piping connections would be used to allow WTP discharge to supplemental LAW processing.

A comprehensive discussion of IX using sRF is presented in 24590-WTP-RPT-PT-02-005. The capacity of sRF to exchange sodium ions on the resin with Cs ions in the feed varies with feed cesium $\left[\mathrm{Cs}^{+}\right]$, sodium $\left[\mathrm{Na}^{+}\right]$, potassium $\left[\mathrm{K}^{+}\right]$, and hydroxide ion $\left[\mathrm{OH}^{-}\right]$concentrations and solution temperature. Report 24590-WTP-RPT-RT-07-005, Basis of Recommendation for Spherical Resorcinol Formaldehyde Resin as the Primary Cesium Ion Exchange Resin in the $W T P$, describes the best available equation for estimating the resin cesium capacity. 
Multiple attributes lead to recommending $\mathrm{SRF}$ resin as the ion exchange media for tank farm supplemental pretreatment and as a better choice than CST for Hanford site applications. Both potential choices were evaluated assuming the Cs content either in the eluate (for sRF) or in the media (for CST) is discharged to waste tanks in preparation for delivery as WTP HLW feed. The main evaluation points are listed below. A discussion of each item is also provided.

- $\quad \mathrm{sRF}$ is the qualified, approved baseline ion exchange resin for the WTP pretreatment facility.

- $\quad$ SRF does not pose a risk of agglomeration and column plugging; whereas CST does.

- As an elutable resin, sRF does not generate additional HLW solids for subsequent disposition at WTP.

- The WTP will not be available for disposition of HLW solids by the anticipated SCIX deployment date.

- $\quad$ sRF for SCIX will ensure that downstream WTP IX processes remain effective.

- $\quad$ SRF may be used at higher temperatures.

- $\quad \mathrm{sRF}$ resin procurement expense is estimated to be less than $2 \%$ of that required for CST.

- CST has limited solubility in glass.

- $\quad$ SRF does not require a grinding module.

- $\quad$ SRF will require a disposition path for elution chemicals.

- Alternate elution chemicals may be considered for sRF.

sRF is the qualified, approved baseline ion exchange resin for the WTP pretreatment facility.

As SRF is the IX resin selected for WTP pretreatment, a great deal of Hanford-specific material characterization data is available. Significant resources have already been spent investigating sRF for Cs-removal for Hanford wastes (24590-PTF-RPT-RT-08-001, Rev 0). Substantial sRF testing with actual and simulated Hanford waste has been conducted for WTP, whereas limited equivalent testing has been done with CST.

$\underline{\text { SRF does not pose a risk of agglomeration and column plugging; whereas CST does. }}$

The lower Cs content of Hanford wastes would expend the CST media at a slower rate than will be experienced at SRS, requiring the CST resin to be in service up to ten times longer. Longer CST residence time in the column would present a risk of agglomeration (CCN-023856, A. Pajunen, CST Risk Assessment Report) of the IX column bed (e.g., 70 days at 10 gpm, 140 days at $5 \mathrm{gpm}$ ). Agglomeration behavior, which could plug the resin removal pathways, has not been observed for sRF resin with substantial testing and is not expected, whereas it has been observed with CST. As Hanford wastes are chemically more varied and complex than SRS wastes (as a result of multiple flowsheet processes during weapons material production) more potential mechanisms may exist to cause agglomeration behavior. If CST were used, Hanford-specific agglomeration testing would be required. 
As an elutable resin, sRF does not generate additional HLW solids for subsequent disposition at WTP.

Assuming 56M gallons of tank waste processing through SCIX, sRF generates no additional HLW solids for subsequent disposition at WTP with no increase in HLW glass; whereas CST would be ground, stored as HLW solids in DSTs, and processed though WTP with a 1 to $8 \%$, likely 2 to $4 \%$, increase in HLW glass. With CST use, WTP HLW processing time and costs and HLW waste disposal costs would proportionally increase. Using sRF would not increase the amount of immobilized high level waste (IHLW) because spent sRF can be disposed as LAW. (Also the quantity of spent sRF is only about 7\% of that of CST.) Conversely, using CST for processing $56 \mathrm{M}$ gallons of tank farm (TF) waste ( $80 \%$ of current projected WTP LAW feed volume and $30 \%$ of current WTP HLW feed volume) would increase the volume of IHLW by 1 to $8 \%$, likely 2 to $4 \%$, depending upon CST blending and niobium glass limits, by sending the ground CST resin to the WTP facility (SVF-2009, Rev 0, CST_Calculator.xlsm). This volume increase would in turn increase the HLW canister count by about 250 to 600 (ORP-11242). It would also increase the associated disposal requirements. Since HLW production may ultimately drive WTP mission length, increases in HLW volume would proportionally increase WTP mission length by 6 to 13 months. Processing with sRF material as an average will return 0.11 gallons of 0.1 to $0.2 \mathrm{M}$ weak salt solutions in the regeneration process per gallon of waste processed. Regeneration solution effluent can vary from extremes of $0.45 \mathrm{M}$ nitric acid to $1 \mathrm{M}$ sodium hydroxide so potentially acidic elution streams must be addressed. However, with proper engineering, neither stream is anticipated to pose a major risk to mission or safety. CST returns only about 0.006 gallons of water per gallon of processed waste.

The WTP will not be available for disposition of HLW solids by the anticipated SCIX deployment date.

Until the WTP is operating, Hanford will have no processing path (HLW vitrification facility) for ground CST. If CST were used, and loaded with Cs, it would accumulate in significant amounts ${ }^{4}$ during pretreatment and require extended in-tank storage, thus presenting additional tank mixing and heel cleanout challenges. Agglomeration or "rocking up" in storage is considered a significant risk that will be difficult to address with testing. The ground CST could also exceed WTP mixing capabilities if it is not sufficiently size-reduced. Conversely, SRS has a disposition path for CST as the DWPF is already operational. Also, SRS has less feed to process using SCIX and correspondingly smaller IX media volumes.

\section{$\underline{\text { SRF for SCIX will ensure that downstream WTP IX processes remain effective. }}$}

Maintaining consistent pretreatment processes ensures new variability is not introduced into the WTP flowsheet. Most Hanford wastes will be subjected to caustic leaching and elevated temperatures (up to $5 \mathrm{M}$ sodium hydroxide $[\mathrm{NaOH}]$ at $85^{\circ} \mathrm{C}$ ) as part of the process to separate aluminum (Al) from the solids fraction. If CST were used for supplemental pretreatment, partial

\footnotetext{
${ }^{4}$ SRS anticipates processing about $26 \mathrm{M}$ gallons of feed using SCIX. Hanford anticipates processing 40-60 M gallons of feed using SCIX.
} 
dissolution of ground CST in the WTP caustic leaching step might lead to $<0.1 \mu$ particles of complexed Cs that could pass through the WTP filtration and IX (sRF) pretreatment, defeating Cs decontamination. Although this scenario is unlikely, the accompanying risk is so high that it would require investigation (involving time and expense) to ensure it would not be an issue.

\section{$\underline{\text { sRF may be used at higher temperatures. }}$}

The $\mathrm{sRF}$ resin may be operated at temperatures of up to $45^{\circ} \mathrm{C}$. CST is limited to $35^{\circ} \mathrm{C}$. (SCIX Presentation to EM-TEG, 9-01-2010). The sRF resin provides greater flexibility for high temperature operation, which can allow higher temperature salt dissolution rates and associated increased waste tank retrieval rates. Higher temperature operation can also reduce the oxalate and phosphate load on the WTP by allowing more dissolution of these salts in the feed streams to supplemental LAW with less remaining in the feed streams sent to WTP.

SRF resin procurement expense is estimated to be less than $2 \%$ of that required for CST.

It has been estimated that processing 56 million gallons of waste feed using SCIX (assuming 6.4 $\mathrm{M}$ sodium, $0.066 \mathrm{M}$ potassium, 3.8E-5 $\mathrm{M}$ cesium, $1.65 \mathrm{M}$ hydroxide and $80^{\circ} \mathrm{F}$ feed temperatures) would require about 4,900 gallons of $\mathrm{sRF}$ resin at a total material cost of about $\$ 3 \mathrm{M}$. To process an equal amount of feed under the same conditions, it has been estimated that about 68,000 gallons of CST would be required at a total material cost of about $\$ 190 \mathrm{M}$. These dollar numbers represent the capital expense of purchasing the required amounts of IX media. They do not include subsequent costs associated with immobilizing CST HLW solids, or spent sRF resin LAW disposal. Disposition of larger amounts of HLW CST solids (68,000 gallons) would be disproportionately more expensive than smaller amounts of sRF LAW (4,400 gallons in hydrogen-form) (SCIX Presentation to EM-TEG, 9-01-2010 and SVF-2009, Rev 0.)

\section{CST has limited solubility in glass.}

Crystalline Silicotitanate is an inorganic material that may be successfully melted into glass in limited quantities. CST, Ionsiv ${ }^{\circledR}$ IE-911 ${ }^{\mathrm{TM}}$ is composed primarily of Soda $\left(\mathrm{Na}_{2} \mathrm{O}\right)$, Silica $\left(\mathrm{SiO}_{2}\right)$, Titania $\left(\mathrm{TiO}_{2}\right)$ and trade secret materials for the binding matrix. Niobium is one of the trade secret constituents. Niobium has been identified as a glass limiter. Titania has been successfully used as an additive to waste glasses. However, Titania is a refractory oxide that is commonly used in commercial applications as a nucleation material for controlled crystallization of glassceramics. (Varshenaya, Fundamentals of Inorganic Glasses, page 83). Waste glasses, particularly those processed in joule-heated ceramic melters, can incorporate Titania to a limited degree, based on the melt temperature, tolerance for crystallization and other factors (PNL10359, Vol. 1 and 2; PNNL-19372; RPP-RPT-42649, Rev. 0).

An evaluation was made of the expected IHLW impacts of processing $80 \%$ of the current projected WTP LAW feed volume plus $30 \%$ of the current HLW feed volume through SCIX using CST media taking into account the solubility of CST in Hanford HLW glass. The resultant $56 \mathrm{M}$ gallons of feed would require 68,000 gallons of CST that would be processed through the WTP as new HLW feed. This is expected to increase the IHLW production by 2 to $4 \%$ (SVF2009, Rev 0). 
Alternate elution chemicals may be considered for sRF.

The current baseline elution chemical is dilute $(0.45$ to $0.1 \mathrm{M})$ nitric acid. There is some concern, from a nuclear hazards viewpoint, regarding potential chemical corrosion of the carbon steel waste tanks in the event acid is discharged directly to them. Procedural, design and mechanical controls will be needed to prevent direct contact of acid with the carbon steel waste tank liners. In addition, a testing campaign is underway at Savannah River National Laboratory (SRNL) to evaluate potential alternate elution agents for the sRF resin. Scoping tests are complete (SRNL-STI-2010-00563) and the next iteration of testing using the top non-acid candidates (e.g. sodium carbonate and sodium acetate) in a flow-through column test configuration is being planned.

\subsection{SRS OPTIONS}

As the primary scope of this document is to aid decisions regarding the Hanford Site, less detail regarding SRS SCIX strategies will be discussed.

The original DWPF plan was to vitrify coupled feed, i.e. sludge and high activity salt waste. However, the separations technology to deliver the salt fraction of the feed did not function as planned and DWPF opted to begin radioactive operations using a sludge-only flowsheet. As a result, much of the SRS sludge solids have already been vitrified, leaving predominantly salt waste to process. This condition has been described as a "salt gap" (SRR-LWP-2009-00001). During engineering evaluations, IX processes were identified and investigated as potential candidates for salt processing. To mitigate the salt gap, several solutions were proposed. One of the solutions was to use SCIX for MSP. MSP is a supplemental method planned to augment the SRS Facility SWPF. Current projections are that MSP will be operational by early FY14 and will process a total of $26,250 \mathrm{kgal}$ of salt solution (SRR-LWP-2009-00001). The MSP will use rotary microfiltration (RMF) to filter feed solids and SCIX to remove Cs, deployed in DST tank risers. A formal engineering evaluation was performed in 2008 to identify the optimal SCIX method to support MSP (G-ADS-H-00014). That engineering study selected in-riser IX columns in lead-lag configuration using CST IX media.

After the CST media is fully-loaded with Cs (to the extent allowable), the material will be sluiced to a grinding module. The resultant ground CST material is more compatible with the overall rheology of the tank waste and meets DWPF sampler criteria (G-ADS-H-00014). After the spent CST is completely sluiced from the column (2+ batches), ground, and discharged to the waste tank, the column will be recharged with fresh CST. The fresh column will become the new lag column and IX operations will be resumed. The formal system engineering evaluation selected CST media based on the following criteria:

- Substantial SRS actual and simulant waste testing had been performed with CST.

- $\quad$ CST is currently being used at Oak Ridge National Laboratory (ORNL) to treat liquid wastes. 
- The DWPF is available as a disposition method for spent HLW CST solids, and the extra titanium impact (due to glass solubility limits) on the number of DWPF canisters was judged to be acceptable.

- Significant modifications of DWPF (cost and downtime) would be required to process the nitric acid used to elute the $\mathrm{sRF}$ resin. (The evaluation did not consider lowering acid concentration after titration of the resin to minimize nitrate addition to the process.)

- Mercury (Hg) in SRS tank wastes created a resin disposal uncertainty.

This process is discussed further in Appendix B.

\subsection{COMPARISON OF sRF AND CST FOR HANFORD SCIX APPLICATIONS}

DOE has stated that resources, technologies, process development and engineering design within the weapons complex should be communicated and shared among the waste producer sites wherever advisable to minimize duplication of effort. This communication enables leveraging of technology and demonstrates good stewardship of American resources.

The Hanford Site and SRS shared a common goal to produce nuclear defense materials during the Cold War. They continue to share a common goal to clean up legacy wastes generated during weapons production. While they are united in this waste cleanup mission, the specific requirements for each site to achieve that mission are similar, yet different. Hanford, as the first site, deployed multiple and varied process flowsheets before identifying the most effective chemical processing methods for weapons production. SRS benefitted from those lessonslearned. As a result the SRS wastes are less varied and more easily characterized. Many of the waste management tactical strategies for Hanford and SRS may be shared, but variations in the nature of the wastes, waste tanks and mission positioning ${ }^{5}$ influence which engineering designs can be deployed.

Multiple factors illustrate the need to tailor the selection of the IX media and SCIX designs to be site-specific. Each site has unique conditions that guide materials selection. Table 1 provides a direct comparison for the technical rationale used for recommending use of sRF for SCIX at Hanford.

\footnotetext{
${ }^{5}$ Mission positioning refers to schedule point in the technical mission. In this instance, SRS is further into their Waste Management mission than the Hanford Site is because they already have operational waste immobilization facilities. However, since SRS has been operating their vitrification facility using a sludge-only flowsheet, they are experiencing a "salt-gap" (described in Section 3.2) in their mission, that Hanford should be able to avoid using lessons-leaned from the SRS mission experience.
} 
Table 1. Comparison of sRF Resin for Hanford vs. CST media for SRS.

\begin{tabular}{|c|c|c|}
\hline $\begin{array}{c}\text { Potential } \\
\text { Behavior/Concern }\end{array}$ & Hanford Site & Savannah River Site \\
\hline Agglomeration & $\begin{array}{l}\text { sRF does not agglomerate. } \\
\text { CST would be in service long enough ( }>70 \\
\text { days) to risk column plugging. CST } \\
\text { discharged to the tanks would risk } \\
\text { accumulation of agglomerated Cs-rich CST } \\
\text { solids that might be difficult to recover. }\end{array}$ & $\begin{array}{l}\text { Due to the high Cs content in SRS wastes, } \\
\text { the CST will not remain in column long } \\
\text { enough to present agglomeration concerns. } \\
\text { The DWPF provides an operational } \\
\text { disposition path for CST to prevent } \\
\text { accumulation of CST in the waste tanks. }\end{array}$ \\
\hline Secondary HLW & $\begin{array}{l}\text { Spent sRF beads will be eluted of Cs prior } \\
\text { to disposal. Spent sRF beads will not be } \\
\text { HLW. } \\
\text { Nitric acid eluant will contain Cs. The } \\
\text { eluant must be chemically neutralized prior } \\
\text { to discharge to the waste tanks or an } \\
\text { alternate disposal/processing pathway } \\
\text { should be found to prevent the need to } \\
\text { perform IX again downstream. } \\
\text { It has been calculated (SVF-2009, Rev } 0 \text {, } \\
\text { CST Calculator.xlsm ) that using CST at } \\
\text { Hanford would likely result in an additional } \\
2 \text { to } 4 \% \text { volume of HLW glass. Using CST } \\
\text { would increase the IHLW canister count by } \\
250 \text { to } 600 \text { canisters and potentially } \\
\text { increase the mission length by } 6 \text { to } 13 \\
\text { months. (ORP-11242, Rev. } 4 \text { ). In addition, } \\
\text { the CST HLW solids would pose mixing } \\
\text { uncertainties that would require study with } \\
\text { respect to tank retrieval and WTP mixing. } \\
\text { ( } 24590 \text {-WTP-ICD-MG-01-019). }\end{array}$ & $\begin{array}{l}\text { The spent CST media will be fully loaded } \\
\text { with Cs and become a secondary HLW } \\
\text { solids stream requiring vitrification. }\end{array}$ \\
\hline Effluent streams & $\begin{array}{l}\text { sRF resin generates Cs-rich nitric acid } \\
\text { eluant. This eluant must either be pre- } \\
\text { neutralized and returned to the tank or } \\
\text { isolated and stored for subsequent } \\
\text { processing. } \\
\text { Process water and caustic regeneration } \\
\text { solutions are process effluents that could be } \\
\text { returned to the tanks. }\end{array}$ & $\begin{array}{l}\text { Effluents will include ground CST, caustic } \\
\text { and water. The CST would be HLW solids } \\
\text { that would require vitrification. }\end{array}$ \\
\hline $\begin{array}{l}\text { Hydrogen }\left(\mathrm{H}_{2}\right) \\
\text { generation }\end{array}$ & $\begin{array}{l}\text { Both sRF and CST have possible } \mathrm{H}_{2} \\
\text { generation issues being investigated. } \\
\text { CST has slower absorption kinetics and } \\
\text { requires a larger resin bed for the same } \\
\text { decontamination and flow rate. Combined } \\
\text { with CST's higher Cs absorption capacity, } \\
\text { CST has substantially higher potential for } \\
\text { hydrogen generation in the IX column. }\end{array}$ & $\begin{array}{l}\text { Both sRF and CST have possible } \mathrm{H}_{2} \\
\text { generation issues being investigated. } \\
\text { CST has slower absorption kinetics and } \\
\text { requires a larger resin bed for the same } \\
\text { decontamination and flow rate. Combined } \\
\text { with CST's higher Cs absorption capacity, } \\
\text { CST has substantially higher potential for } \\
\text { hydrogen generation in the IX column. }\end{array}$ \\
\hline
\end{tabular}


RPP-47630, Rev. 0

\begin{tabular}{|c|c|c|}
\hline $\begin{array}{c}\text { Potential } \\
\text { Behavior/Concern }\end{array}$ & Hanford Site & Savannah River Site \\
\hline Melter environment & $\begin{array}{l}\text { The Hanford WTP feed chemistry is } \\
\text { controlled to ensure the appropriate } \\
\text { oxidation/reduction environment in the } \\
\text { melter. The melter will not be impacted by } \\
\text { sRF acid elution streams, particularly since } \\
\text { sRF IX is already accounted for by the } \\
\text { WTP LAW vitrification flowsheet. }\end{array}$ & $\begin{array}{l}\text { Though CST will increase canister count, it } \\
\text { is chemically compatible with the DWPF } \\
\text { downstream processes. The sRF acid eluant } \\
\text { streams could interfere with the DWPF } \\
\text { processing envelope. }\end{array}$ \\
\hline Media discharge & $\begin{array}{l}\text { Spent sRF beads will be eluted of Cs prior } \\
\text { to disposal. The current baseline is to } \\
\text { fluidize the beads and sluice them from the } \\
\text { column. They will then be dried and } \\
\text { disposed to a HIC. } \\
\text { Other alternatives that could process the } \\
\text { spent sRF beads into a waste form are being } \\
\text { investigated. }\end{array}$ & $\begin{array}{l}\text { The spent CST will be mechanically } \\
\text { ground to a particle size consistent with } \\
\text { sludge solids prior to discharge to the tank. } \\
\text { This step is included to improve waste } \\
\text { rheology and prevent stratification of large } \\
\text { particles of CST in the waste tank. The } \\
\text { spent CST will be HLW and require } \\
\text { vitrification. }\end{array}$ \\
\hline Disposition path & $\begin{array}{l}\text { The Hanford Site can accommodate } \\
\text { disposition of spent SRF resin. } \\
\text { The Hanford Site does not currently have } \\
\text { an operational disposition path (WTP) for } \\
\text { CST. } \\
\text { The capability of the WTP black cell } \\
\text { vessels to suspend ground CST would need } \\
\text { to be confirmed. }\end{array}$ & $\begin{array}{l}\text { The DWPF is a viable disposition pathway } \\
\text { for CST. }\end{array}$ \\
\hline $\begin{array}{l}\text { WTP cesium removal } \\
\text { needs }\end{array}$ & $\begin{array}{l}\text { Both CST and sRF SCIX will return } \\
\text { captured Cs to tank feed to the WTP. With } \\
\text { sRF this feed can go either into WTP Feed } \\
\text { Receipt Process Tanks FRP-2A/B/C/D or } \\
\text { High Level Waste Lag Storage tanks HLP- } \\
22 \text {. With CST it must go into HLP- } 22 \text { with } \\
\text { some Cs released back to soluble form and } \\
\text { some still captured by the resin. Both } \\
\text { strategies rely on WTP IX to lower the Cs } \\
\text { concentrations to meet LAW glass feed } \\
\text { limits. }\end{array}$ & Not applicable \\
\hline
\end{tabular}

A meeting was held in April 2010, with representatives from SRS and Hanford to identify sitespecific SCIX functional requirements. The purpose was to document the fact that the Hanford Site and SRS have different processing requirements, capabilities and waste compositions that preclude complete duplication of the SCIX design. Two site-specific summaries of SCIX were compiled during the meeting and are provided in Appendix A and Appendix B. The information provided in Table 1 is consistent with the assessments generated during that April 2010 meeting.

\footnotetext{
${ }^{6}$ WTP black cells are inaccessible to maintenance (e.g. crane and camera operations) after radioactive commissioning.
} 


\subsection{SPHERICAL RESORCINOL FORMALDEHYDE MATERIAL PROPERTIES}

The IX capacity for a column is ion specific and is measured as the number of available IX sites, in milli-moles ( $\mathrm{mmol}$ ), divided by the resin mass measured in grams. Actual total capacity reported for earlier forms of $\mathrm{sRF}$ range from 1.5 to $6.83 \mathrm{meq} / \mathrm{g}$, and a total capacity of $6 \pm 0.8$ $\mathrm{meq} / \mathrm{g}$ dry hydrogen form (H-form) resin was recommended for modeling $\mathrm{sRF}$ from resin lot $5 \mathrm{E}$ 370/641 (WSRC-STI-2006-00071, Batch, Kinetics, and Column Data from Spherical Resorcinol-Formaldehyde Resin). A total resin capacity of $6.8 \mathrm{meq} / \mathrm{g}$ dry H-form resin (or 6.8 $\mathrm{mmol} / \mathrm{g}$ dry H-form resin) has been used to evaluate batch equilibrium data for $\mathrm{sRF}$ for use in WTP pretreatment.

The chemistry considerations for the SRF WTP pretreatment applications are directly relevant for supplemental pretreatment of LAW salt waste. However, some aspects of this deployment strategy will be scaled down and tailored to meet the requirements of the RMF-SCIX application. In particular, the elution strategy will be changed to minimize the volume of effluent solutions and the quantity of nitrate in the eluant. The SCIX system will be designed to optimize Cs loading with respect to elution schedules and resin limitations. The upper limit allowed on curie loading before elution is a trade-off between radiolytic decay heat loading and $\mathrm{H}_{2}$ generation, $\mathrm{Cs}$ loading, and resin damage from radiation. High Cs loading is desirable, while high heat and $\mathrm{H}_{2}$ generation and resin damage are not. The technical safety requirement for WTP is to not exceed 150,000 curies for a 600 -gallon bed giving a maximum of about 740 watts of energy. WTP will typically limit loading to 75,000 curies.

The upper Cs load limit in the in-tank riser application will likely be driven by hydrogen generation rate and maximum allowable downtime with associated hydrogen build-up before elution. Because back-pressure increases hydrogen solubility (per Henry' Law) ${ }^{7}$, normal flow rates will dissolve and carry away any generated hydrogen. Hydrogen accumulation is normally only possible during a non-flow condition where the product of time without flow and column Cs loading determine the possible hydrogen accumulation. To provide tolerance for some hydrogen accumulation, the column will be designed to withstand substantially more pressure than the pressure relief setting - likely requiring a $3 / 8$ to $1 / 2$-inch wall thickness. Water-cooling the shell of the IX column with temperature indication in both the resin bed and the cooling jacket will mitigate heat generation issues associated with Cs loading and provide secondary containment.

There has been some concern that the baseline acid elution methods used for sRF could potentially damage the structural integrity of the carbon steel liner of the DST that is used for the in-riser SCIX system. Modest volumes ${ }^{8}$ of dilute nitric acid $(0.5$ to $0.1 \mathrm{M})$ are used to elute the $\mathrm{Cs}$ from the $\mathrm{sRF}$ resin beads. Conceptual engineering designs to mitigate or eliminate this concern are being considered. Plans are to create a doubly contained stainless steel vessel that is suspended within the DST containing the SCIX system through the central riser, where dilute acid eluant, and other process fluids, may be intermingled with caustic tank supernatant using static mixing technology to neutralize any acid hazard to the DST. Redundant instruments

\footnotetext{
${ }^{7}$ Henry's law is a chemical law stating that the amount of a gas that dissolves in a liquid is proportional to the partial pressure of the gas over the liquid, provided no chemical reaction takes place between the liquid and the gas. ${ }^{8}$ Approximately 6,000 gallons of dilute nitric acid per 300-gallon sRF resin bed elution cycle are projected.
} 
would be installed in the system to monitor the neutralization process and shut it down if any indications of inadequate neutralization were detected in the neutralization tank before the waste was discharged back to the DST. The neutralized solutions would then be discharged beneath the liquid level of the tank to further ensure the continued integrity of the carbon steel liner. Engineering and procedural controls would be implemented to further guarantee that any acid eluants would not contact the tank liner. Inhibited water and caustic solutions are also part of the resin elution and regeneration process. Figure 5 is a preliminary, pre-conceptual design for preneutralizing SCIX eluants. The DST receipt tank would likely be equipped with a wiped film evaporator to assist in removing excess water discharged to the tank as part of the elution process. 
Figure 5. Pre-conceptual Engineering Design for Neutralizing sRF Acid Eluants.

\section{DOUBLE CONTAINED ACID ELUENT STREAM NEUTRALIZATION TANK DESIGN CONCEPT}

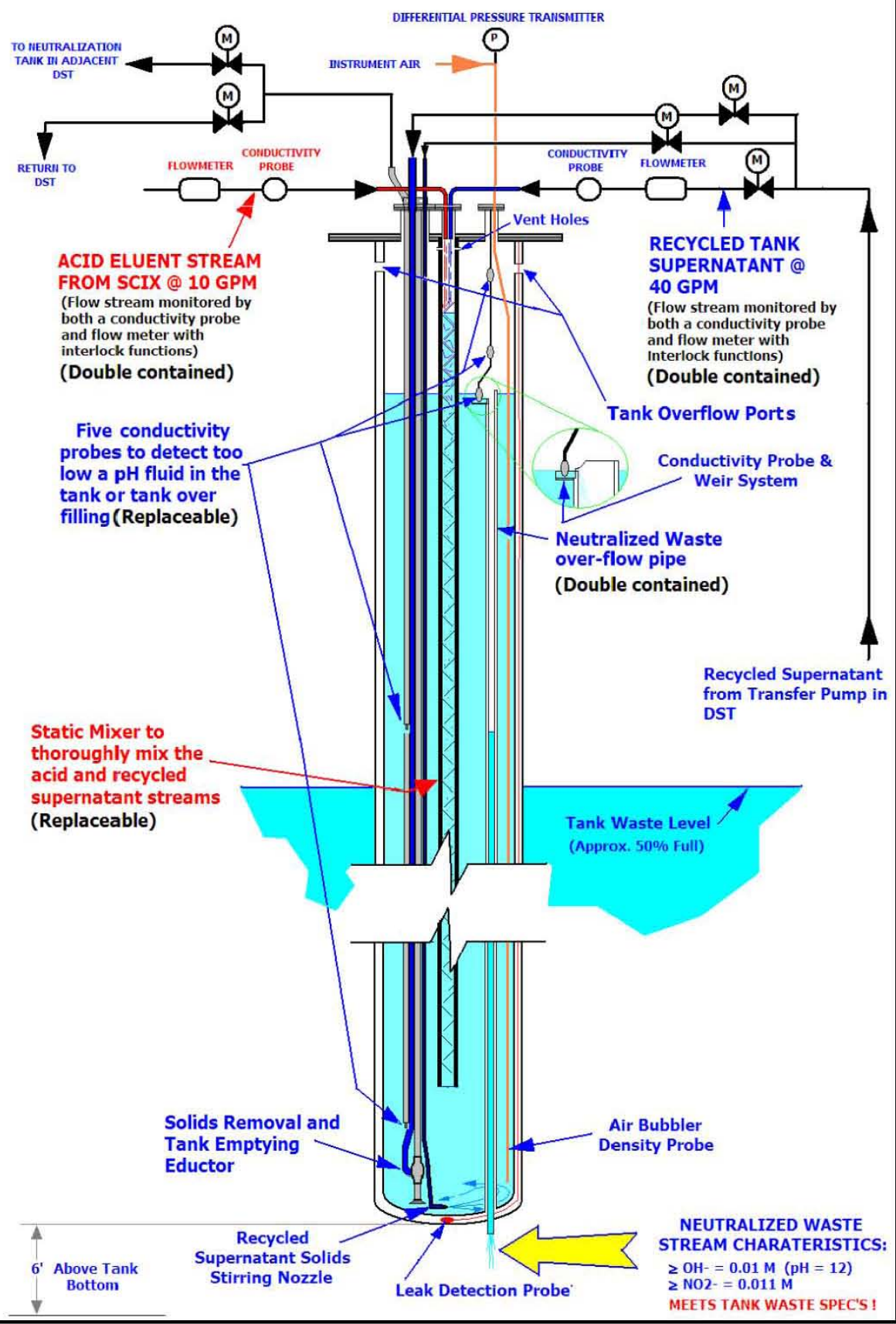


Table 2. Restoration Steps and Time for a 37" Diameter, 300-Gallon Bed of SCIX sRF Resin Using Recommended Flow Rates and Minimum Elution Volumes.

\begin{tabular}{|c|c|c|c|c|c|c|c|c|c|}
\hline \multicolumn{10}{|c|}{ RF SCIX restoration steps and time using recommended flow rates and minimum restoration volumes } \\
\hline Step & Reagent & $\begin{array}{l}\text { Flow in } \\
\text { gpm }\end{array}$ & $\begin{array}{l}\text { fresh resin } \\
\text { bed } \\
\text { volume in } \\
\text { gallons at } \\
\text { flow } \\
\text { conditions } \\
\end{array}$ & $\begin{array}{l}\text { Gallons } \\
\text { processed }\end{array}$ & $\begin{array}{l}\text { (BV) } \\
\text { processed } \\
\text { (relative to } \\
\text { Na-form } \\
\text { settled } \\
\text { volume) } \\
\end{array}$ & $\begin{array}{l}\text { BV/hr } \\
\text { (relative to } \\
\text { Na-form } \\
\text { settled } \\
\text { volume) } \\
\end{array}$ & $\begin{array}{l}\text { Hours for } \\
\text { step }\end{array}$ & $\begin{array}{l}\text { Estimated } \\
\text { switch time } \\
\text { after this } \\
\text { step }\end{array}$ & $\begin{array}{l}\text { Hours for } \\
\text { step plus } \\
\text { switch } \\
\text { time }\end{array}$ \\
\hline Displacement & $0.1 \mathrm{M} \mathrm{NaOH}$ & 15.0 & 297 & 540 & 1.80 & 3.00 & 0.60 & 0.05 & 0.65 \\
\hline $\begin{array}{l}\text { Resin removal line displacement (flow rate } \\
\text { to be determined) }\end{array}$ & DIW & 3.4 & 297 & 7 & 0.00 & 0.00 & 0.03 & 0.05 & 0.08 \\
\hline Pre-elution rinse & DIW & 15.0 & 290 & 240 & 0.80 & 3.00 & 0.27 & 0.05 & 0.32 \\
\hline $\begin{array}{l}\text { Nitric acid elution (concentration may be } \\
\text { lowered after resin titration if this benefits } \\
\text { CNP system) }\end{array}$ & $\begin{array}{l}0.45 \mathrm{M} \text { then } 0.1 \mathrm{M} \\
\mathrm{HNO} 3\end{array}$ & 7.0 & 234 & 4,579 & 15.26 & 1.40 & 10.90 & 0.05 & 10.95 \\
\hline $\begin{array}{l}\text { Resin removal line elution after } 1 \text { st } 7 \text { BV of } \\
\text { previous bed elution (flow rate to be } \\
\text { determined) }\end{array}$ & $0.45 \mathrm{M} \mathrm{HNO} 3$ & 2.9 & 234 & 7 & 0.00 & 0.00 & 0.04 & 0.05 & 0.09 \\
\hline Post-elution rinse & DIW & 7.0 & 234 & 540 & 1.80 & 1.40 & 1.29 & 0.05 & 1.34 \\
\hline Resin removal line regeneration & $>0.2 \mathrm{M} \mathrm{NaOH}$ & 15.0 & & 7 & 0.00 & 0.00 & 0.01 & 0.05 & 0.06 \\
\hline Upflow regeneration, step 1 & $1 \mathrm{M} \mathrm{NaOH}$ & 22.8 & 421 & 534 & 1.78 & 4.56 & 0.39 & 0.05 & 0.44 \\
\hline No flow to settle bed & $1 \mathrm{M} \mathrm{NaOH}$ & 0.0 & 295 & - & 0.00 & 0.00 & 0.08 & 0.05 & 0.13 \\
\hline Upflow regeneration, step 2 & $1 \mathrm{M} \mathrm{NaOH}$ & 3.6 & 300 & - & 0.00 & 0.72 & 0.00 & 0.05 & 0.05 \\
\hline Upflow displacement of regeneration fluid & Polished LAW Feed & 4.6 & 420 & 617 & 2.06 & 0.92 & 2.24 & 0.05 & 2.29 \\
\hline Upflow displacement of regeneration fluid & Polished LAW Feed & 7.3 & 492 & - & 0.00 & 1.47 & 0.00 & 0.05 & 0.05 \\
\hline $\begin{array}{l}\text { Purge of sampler line to polish column } \\
\text { (concurrent with bed settling and at load } \\
\text { flow rate) }\end{array}$ & Polished LAW Feed & 10.0 & & 18 & 0.00 & 0.00 & 0.03 & 0.05 & 0.08 \\
\hline Bed settling & Polished LAW Feed & 0.0 & 305 & - & 0.00 & 0.00 & 0.48 & 0.05 & 0.53 \\
\hline Subtotal, without polished LAW feed & & & & 6,455 & & & & & \\
\hline Total & & & & & & & 16.3 & & 17.0 \\
\hline
\end{tabular}


Table 2 and Figure 6 represent preliminary estimates of the elution parameters and schedules anticipated for SCIX. Figure 6 illustrates the anticipated number of elution cycles, versus volume of feed treated, for a range of anticipated waste compositions. The figure graphically represents the resin degradation that occurs over time. The higher activity feeds will result in more frequent elution and replacement of the sRF IX resin bed.

All concentrations in Table 2 are provided in moles per liter (M). This information is considered a reliable estimate for planning purposes, but is not a WRPS-approved, calculated worksheet. This estimate trims the restoration cycle to an essential minimum as shown in Table 2 for minimum total dilute effluent.

Figure 6. Resin Load Volume as a Function of Cycle for Representative Hanford Wastes.

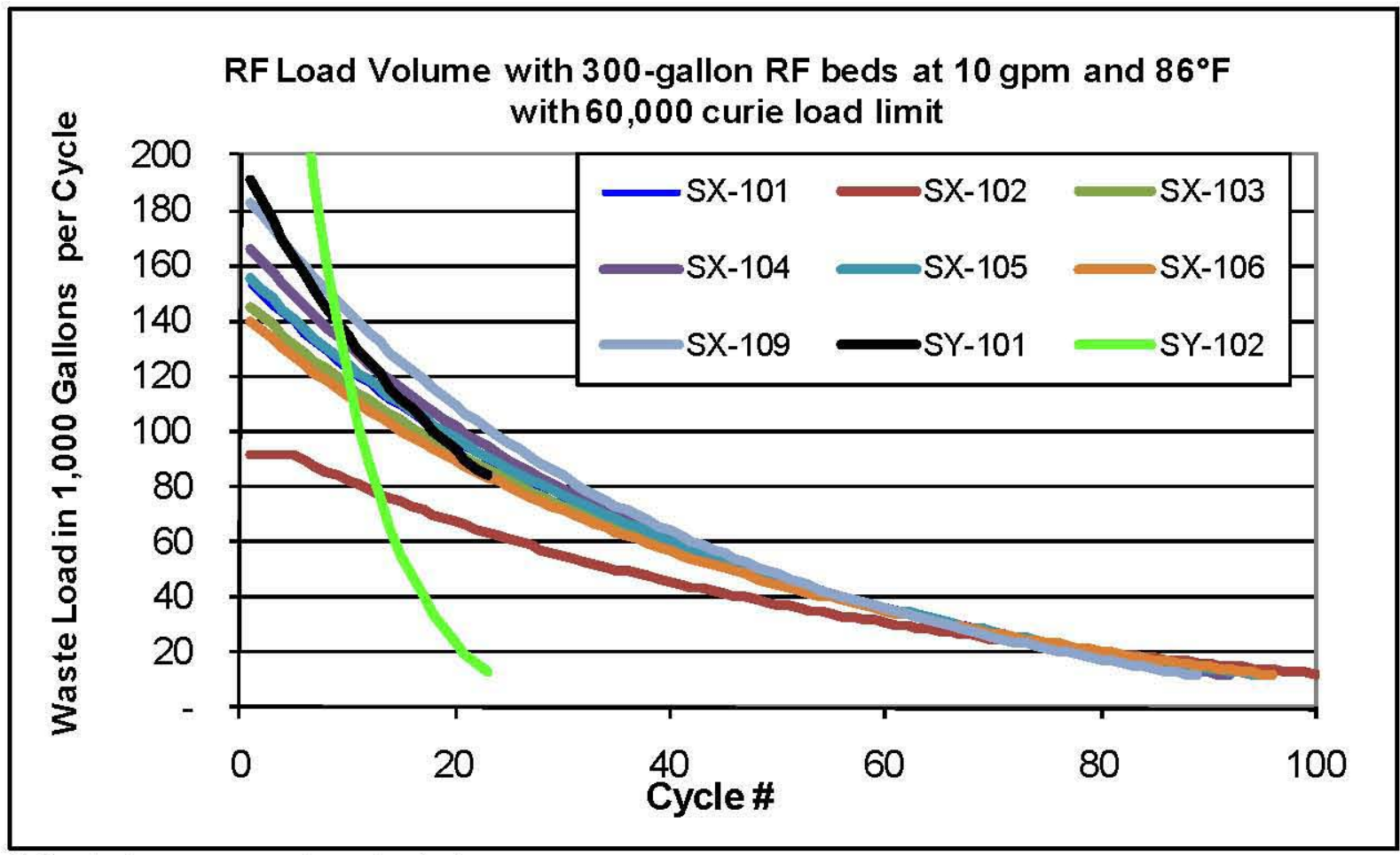

Calculation assumptions include:

SX-101: sRF Load Volume with 300-gallon resin beds at $10 \mathrm{gpm}$ using the average of

SX-101 tank feeds at $30^{\circ} \mathrm{C} ;[\mathrm{Na}]=5 ;[\mathrm{K}]=0.0121 ;[\mathrm{OH}-]=5.3 ;[\mathrm{Cs}+]=0.000023$;

Fraction $\mathrm{Cs}-137=0.2$ (Note that $[\mathrm{OH}-]$ is not possible, too high for $[\mathrm{Na}]$.)

SX-102: sRF Load Volume with 300-gallon resin beds at $10 \mathrm{gpm}$ using the average of

SX-102 tank feeds at $30^{\circ} \mathrm{C} ;[\mathrm{Na}]=5 ;[\mathrm{K}]=0.0273 ;[\mathrm{OH}-]=2.03 ;[\mathrm{Cs}+]=0.000073$;

Fraction $\mathrm{Cs}-137=0.2$

SX-103: sRF Load Volume with 300-gallon resin beds at $10 \mathrm{gpm}$ using the average of

SX-103 tank feeds at $30^{\circ} \mathrm{C} ;[\mathrm{Na}]=5 ;[\mathrm{K}]=0.0218 ;[\mathrm{OH}-]=1.37 ;[\mathrm{Cs}+]=0.000028$;

Fraction Cs-137 $=0.2$

SX-104: sRF Load Volume with 300-gallon resin beds at $10 \mathrm{gpm}$ using the average of

$\mathrm{SX}-104$ tank feeds at $30^{\circ} \mathrm{C} ;[\mathrm{Na}]=5 ;[\mathrm{K}]=0.0144 ;[\mathrm{OH}-]=1.87 ;[\mathrm{Cs}+]=0.00002$;

Fraction $\mathrm{Cs}-137=0.2$

SX-105: sRF Load Volume with 300-gallon resin beds at $10 \mathrm{gpm}$ using the average of 
SX-105 tank feeds at $30^{\circ} \mathrm{C} ;[\mathrm{Na}]=5 ;[\mathrm{K}]=0.0251 ;[\mathrm{OH}-]=3.01 ;[\mathrm{Cs}+]=0.000022$; Fraction Cs-137 $=0.2$

SX-106: sRF Load Volume with 300-gallon resin beds at 10 gpm using the average of $\mathrm{SX}-106$ tank feeds at $30^{\circ} \mathrm{C} ;[\mathrm{Na}]=5 ;[\mathrm{K}]=0.021 ;[\mathrm{OH}-]=2.14 ;[\mathrm{Cs}+]=0.000031$; Fraction Cs-137 $=0.2$

SX-109: sRF Load Volume with 300-gallon resin beds at $10 \mathrm{gpm}$ using the average of SX-109 tank feeds at $30^{\circ} \mathrm{C} ;[\mathrm{Na}]=5 ;[\mathrm{K}]=0.0079 ;[\mathrm{OH}-]=3.24 ;[\mathrm{Cs}+]=0.000015$; Fraction $\mathrm{Cs}-137=0.2$

SY-101: sRF Load Volume with 300-gallon resin beds at 10 gpm using the average of $\mathrm{SY}-101$ tank feeds at $30^{\circ} \mathrm{C} ;[\mathrm{Na}]=4.06 ;[\mathrm{K}]=0.019 ;[\mathrm{OH}-]=2.36 ;[\mathrm{Cs}+]=0.000028$; Fraction $\mathrm{Cs}-137=0.2$

SY-102: sRF Load Volume with 300-gallon resin beds at $10 \mathrm{gpm}$ using the average of SY-102 tank feeds at $30^{\circ} \mathrm{C} ;[\mathrm{Na}]=1.92 ;[\mathrm{K}]=0.0055 ;[\mathrm{OH}-]=0.48$;

$[\mathrm{Cs}+]=0.000009$; Fraction $\mathrm{Cs}-137=0.2$ (Note that the $1^{\text {st }} 6$ cycles are off scale, with the $1^{\text {st }}$ cycle starting at $485 \mathrm{~K}$ gallons.)

There are many trade-offs in the load volume selection. Some of the trade-offs are:

- A lack of adequate displacement leads to in-bed precipitation that is then dissolved into the eluant acid.

- A pre-elution rinse deficiency leads to some waste (neutralization) of elution acid.

- An elution volume deficiency leads to "Cs bleed" from the restored resin.

- The lack of post-elution rinse leads to "Cs bleed" from the restored resin (effectively part of the elution step) and some inefficient acid and caustic use or neutralization.

- A regeneration deficiency leads to in-bed precipitation during LAW introduction with subsequent problems.

- The lack of up-flow displacement leads to an out-of-level resin bed with resulting inefficiencies and issues.

The load cycle graph, Figure 6, is for projected feed composition from each tank using data provided by others. The stated hydroxide concentration in SX-101 is too high to be correct considering the sodium concentration, but correcting this figure should have negligible effect on the calculated load volumes. All calculations assume a nominal resin bed volume of 300 gallons (37' ID, 65.7" deep) for fresh sRF resin volume in $0.5 \mathrm{M} \mathrm{NaOH}$. The resin bed volume in $0.5 \mathrm{M}$ $\mathrm{NaOH}$ will increase by about $25 \%$ if the resin is used to exhaustion. The column internal volume is assumed to be 600 gallons. All load cycles are at $10 \mathrm{gpm}$ and fluids at $86^{\circ} \mathrm{F}$. The restoration conditions for fresh resin are shown in Table 2. All restoration chemicals are at $77^{\circ} \mathrm{F}$ or cooler except the up-flow feeds ( $1 \mathrm{M} \mathrm{NaOH}$ and polished LAW), which are at $86^{\circ} \mathrm{F}$ (same as the waste processing temperature). A $1 \mathrm{M} \mathrm{NaOH}$ was used for the up-flow regeneration step instead of 0.5 $\mathrm{M}$ (the WTP standard) to reduce the total quantity of new liquid added with each restoration cycle $(6,455$ gallons). If feasible, the total process including IX will run better at higher sodium content in the waste feed due to less soluble oxygen. Therefore, if less waste feed dilution is required, this approach is recommended. A lead-lag column arrangement was used, with the lead column loaded lightly so the effluent of the lead column would be well below the $\mathrm{Cs}$ concentration limits for WTP LAW processing ( 0.3 curies per cubic meter of LAW glass) when the other loaded column is being eluted. (Only two IX columns are required for this strategy. 
However, the load rate of the one column (300 gallon resin bed) may need to be lowered to 7.5 gpm, instead of $10 \mathrm{gpm}$, when the other column is being restored.) It is assumed $20 \%$ of the Cs content is ${ }^{137} \mathrm{Cs}$. A 60,000 curie load limit ( $\sim 300$ watts) was used, limiting the first five SX-102 load cycles. The individual curves stop when the load time no longer exceeds the restoration time by at least two hours. In actual operation, the number of cycles before resin disposal will likely be less for multiple reasons including the fact that fewer restoration chemicals will be added per waste volume processed. The values for resin degradation rate from dissolved oxygen and radiation exposure are conservative compared to recent ORNL test results.

\subsection{MATERIAL SUPPLY}

To date, only about 600 gallons of sRF resin have been produced in scaled-up (100-gallon lot) quantities, all for WTP testing purposes, with 400 gallons now stored for future commercial use. Spherical development from concept to the six 100-gallon test production lots occurred from 2002 through 2006. The 100-gallon production lots were produced by Microbeads in Skedsmokorset, Norway and Boulder Scientific Company in Mead, Colorado with all lots meeting or exceeding all WTP requirements. The first commercial orders, all for WTP use, have been placed with several thousand gallons to be delivered over the next five years. A long-term supply strategy meeting the WTP's full mission resin needs has been formulated and is documented in CCN 188891.

The beads on a dry hydrogen-form basis are $99 \%$ composed of resorcinol formaldehyde polymer and $0.6 \%$ composed of a lightly cross-linked polystyrene seed material interspersed throughout. The manufacture process is specialized to create uniform diameter spheres with high durability and high diffusivity to meet WTP Cs removal and resin regeneration needs. Synthesis is protected by patent and trade secret information and includes seed material synthesis, seed preparation, and final resorcinol formaldehyde polymerization. Seed volume is about $0.5 \%$ of final synthesis bead volume. One batch of seeds can produce many batches of beads, sufficient for thousands of gallons of finished resin. Finished resin production of 100 gallons hydrogenform (160 gallons sodium-form) resin requires about four weeks to complete with two weeks utilizing a critical path, 1,300-gallon reactor. As production demand grows, Microbeads has planned equipment changes to allow 100 gallons of hydrogen-form resin production per week.

Microbeads AS advertises sRF on its website (http://micro-beads.com/Home.aspx) and specifically states on the technical datasheet that, "this product will be used in the purification of the radioactive waste at the large waste treatment plant, WTP at Hanford Site, the Washington state USA." A copy of the technical datasheet for sRF may be found in Appendix C.

There is an element of risk in relying on a foreign supplier for a key component of the LAW pretreatment system. There is no indication that there will be any problems obtaining production volumes of sRF material when the time is right. However, in consultation with DOE's Office of River Protection (ORP) and alignment with the plans outlined in CCN 188891, it may be prudent to administer a contract with Microbeads in anticipation of product needs that assures supply needs are met. Options could include allowing use of the production technology for synthesis at alternative sites in the unforeseen event Microbeads is unable to deliver the product itself. Since 
testing has demonstrated that SRF has a long shelf life, when properly stored, provisions could be made to procure the material, or its precursor seed material, in bulk to prevent supply problems.

\subsection{CONCLUSIONS}

SCIX has been identified as a key component of supplemental LAW pretreatment. It is projected that SCIX will be deployed at-tank, and will be preceded by an at-tank filtration step using rotary microfilters. The resulting pretreated LAW may be processed through WTP LAW vitrification, if piping is added to allow direct transfer, or by an alternate waste processing facility such as a Fluidized Bed Steam Reformer (FBSR). SRF is the baseline ion exchange resin for the WTP pretreatment facility and may also be selected as the supplemental LAW treatment SCIX resin.

sRF ion exchange resin is the logical choice for SCIX at the Hanford Site for many reasons. As it has already been selected and developed for use in WTP LAW pretreatment, with minor adaptations to optimize elution schedules and deployment configurations it may be directly implemented for SCIX. In summary:

- DOE may directly leverage all of the sRF technology development for WTP.

- $\quad$ SRF does not generate additional HLW solids.

- $\quad$ RRF does not agglomerate, and as a result will not plug the IX columns.

- Spent sRF may be disposed as LAW. A disposition path for the spent sRF resin has already been identified (disposed to Hanford's Integrated Disposal Facility [IDF] in a HIC).

- $\quad$ sRF provides flexibility for high temperature operation (CST is limited to $35^{\circ} \mathrm{C}$ ), which can allow higher temperature salt dissolution and potentially reduce oxalate and phosphate load on the WTP.

- $\quad \mathrm{SRF}$ is less expensive that CST.

- $\quad$ sRF for SCIX will ensure that downstream WTP IX processes remain effective.

- $\quad$ SRF does not require a grinding module.

In addition, by maintaining pretreatment methods consistent with WTP LAW, supplemental SCIX could also directly support WTP LAW vitrification, with some piping modifications to allow direct LAW feed. This feed pretreatment consistency removes variability and would provide flexibility for the overall LAW processing mission.

In the event that $\mathrm{SRF}$ is selected for SCIX, it will be necessary to define a disposition path for $\mathrm{sRF}$ elution chemicals and ensure that engineering and procedural controls are in place to ensure the structural integrity of the DSTs. 
RPP-47630, Rev. 0

\subsection{REFERENCES}

08-WTP-096, Contract No. DE-AC27-01RVI4136, 2008, Recommendation for use of Spherical Resorcinol Formaldehyde (RF) Resin as the Primary Cesium Ion Exchange Resin in the Waste Treatment and Immobilization Plant (WTP), U.S. Department of Energy, Office of River Protection, Richland, Washington.

24590-WTP-ICD-MG-01-019, 2008, ICD 19-Interface Control Document for Waste Feed, Rev. 3, River Protection Project, Waste Treatment Plant, Richland, Washington.

24590-WTP-RPT-PT-02-005, 2008, Flowsheet Bases, Assumptions and Requirements, Rev. 5, River Protection Project, Waste Treatment Plant, Richland, Washington.

24590-WTP-RPT-RT-06-001, 2008, Basis for Recommendation of Spherical Resorcinol Formaldehyde Resin as the Approved Equivalent to SuperLig 644, River Protection Project, Waste Treatment Plant, Richland, Washington.

24590-WTP-RPT-RT-07-005, 2008, Basis of Recommendation for Use of Spherical Resorcinol Formaldehyde Resin as the Primary Cesium Ion Exchange Resin in the WTP, Rev. 5, River Protection Project, Waste Treatment Plant, Richland, Washington.

CCN-023856, 2001, A. Pajunen, CST Risk Assessment Report, River Protection Project, Waste Treatment Plant, Richland, Washington.

CCN-188891, 2008, M. Thorson, Follow-up to Recommendations for WTP Supply of RF Resin, Meeting Minutes, River Protection Project, Waste Treatment Plant, Richland, Washington.

Contract No. DE-AC27-01RV14136, Section C.7.d.1.iii (U.S. Department of Energy, 2000).

G-ADS-H-00014, 2007, Liquid Waste Operations, Enhanced Processes for Radionuclide Removal Systems Engineering Evaluation, Rev. 0, Washington Savannah River Co, Aiken, South Carolina.

ORP-1 1242, 2009, River Protection Project System Plan, Rev 5, U.S. Department of Energy, Office of River Protection, Richland, Washington.

OSD-T-151-00007, 2009, R. S. Rast, Operating Specifications for the Double-Shell Storage Tanks, Rev. 3, Washington River Protection Solutions, Richland, Washington.

PNL-10359, Vol. 1 and 2, 1994, P. Hrma, et.al., Property/Composition Relationships for Hanford High-Level Waste Glasses Melting at $1150^{\circ} \mathrm{C}$, Pacific Northwest Laboratory, Richland, Washington.

PNNL-11124, 1996, L. A. Bray, et.al., Initial Evaluation of Two Organic Resins and their Ion Exchange Column performance for the Recovery of Cesium from Hanford Alkaline Wastes, Pacific Northwest National Laboratory, Richland, Washington.

PNNL-19372, 2010, J. S. McCloy, J. D. Vienna, Glass Composition Constraint Recommendations for Use in Life Cycle Mission Modeling, Pacific Northwest National Laboratory, Richland, Washington.

RPP-RPT-37741, 2008, Project W-551 Determination Data for Early LAW Interim Pretreatment System Selection, Rev. 0, CH2M HILL Hanford Group, Inc., Richland, Washington. 
RPP-RPT-38057, 2008, Project W-551 Interim Pretreatment System Technology Selection Summary Decision Report and Recommendation, Rev. 0, CH2MHill, Hanford Group, Inc., Richland, Washington.

| RPP-RPT-42649, 2009, J.D. Belsher and F.L. Meinert-, High-Level Waste Glass Formulation Model Sensitivity Study 2009 Glass Formulation Model versus 1996 Glass Formulation Model, Rev. 0, Washington River Protection Solutions, Richland, Washington.

SRNL-STI-2010-00563, 2010, Preliminary Report on Evaluation of Potential Eluants for NonAcid Elution of Cesium from Spherical Resorcinol Formaldehyde Resin, Rev. 0, Savannah River National Laboratory, Aiken, South Carolina.

SRR-LWP-2009-00001, 2010, Liquid Waste System Plan, Rev. 15, Savannah River Remediation, Aiken, South Carolina.

SRR-SCIX-210-00026, 2010, Technology Maturation Plan for the Small Column Ion Exchange Program, Savannah River Remediation, Aiken, South Carolina.

SVF-2009, November 01, 2010, CST_Calculator.xlsm, Rev. 0, Washington River Protection Solutions, Richland, Washington.

Thorson, Murray, 2010, "Presentation to the DOE-EM Technical Expert Group, Small Column Ion Exchange in Support of Supplemental Low Activity Pretreatment." Washington River Protection Solutions, Richland, Washington.

U.S. DOE EM, 2009, Technology Readiness Assessment/Technology Maturation Plan Process Guide, US Department of Energy, Washington, DC.

United States Patent 5,441,991, Jane P. Bibler and R. M. Wallace, Cesium-Specific Phenolic Ion Exchange Resin, as amended, Washington D.C.

Varshenaya, Arun K., Fundamentals of Inorganic Glasses, Academic Press, Inc., copyright 1994, page 83, Harcourt Brace \& Company Publishers, Alfred, New York.

WSRC-STI-2006-00071, 2006, Batch, Kinetics, and Column Data from Spherical ResorcinolFormaldehyde Resin), Savannah River Company, Savannah River Site, Rev. 0, Aiken, South Carolina.

WTP-RPT-135, PNWD-3751, 2006, S.K. Fiskum, et.al., Small Column Ion Exchange Testing of Spherical Resorcinol-Formaldehyde Resin for ${ }^{137} \mathrm{Cs}$ Removal from Pre-Treated Hanford Tank 241-AN-102 Waste (Envelope C), Rev.1, Prepared for Bechtel National Inc. under Contract No. 24590-101-TSA-W0000-00004, Richland, Washington.

WTP-RPT-142, PNWD-3763, 2006, S.T. Arm, et.al., Laboratory Scale Hydraulic Testing of Spherical Resorcinol Formaldehyde Ion Exchange Resins, Rev. 0, Prepared for Bechtel National Inc. under Contract No. 24590-101-TSA-W000-00004, Richland, Washington.

World Wide Web: Microbeads, Ion Exchange Resins, Queried 10/14/2010, Technical Datasheet Dynoseeds $\mathrm{RF} 380$, http://micro-beads.com/Home.aspx. 
RPP-47630, Rev. 0

\section{APPENDIX A - HANFORD SITE SPECIFIC INFORMATION REGARDING ION EXCHANGE MEDIA SELECTION}

(document prepared during April 2010 meeting at SRS) 


\section{SUPPLEMENTAL LAW PROCESSING MISSION ENHANCEMENTS}

- Eliminates the need for second LAW Vitrification Facility

- Potentially eliminates the need for an Aluminum Removal Facility.

- Reduces LAW processing requirements of WTP, and offers an earlier, alternate disposal path for Hanford LAW. This also reduces the potential for bottlenecks at the cross site transfer lines.

- Provides processing flexibility for LAW (LAW vitrification feed may be provided by WTP Pretreatment Facility or by supplemental pretreatment).

- Saves \$6 Billion (assuming start-up of supplemental LAW processing in 12/2017).

- Retains or improves schedule commitments; Helps ensures compliance with Hanford Site Treatment Plan (process all high-level waste by 2045).

\section{Hanford Liquid Waste System Enablers:}

- Demonstrate FBSR mineralized product to be "as good as glass" to facilitate waste acceptance for onsite disposal.

- WTP accepts removed Sr, actinides, and Cs (using elutable spherical resorcinol formaldehyde (sRF) resin in pretreatment); and vitrifies as HLW for disposal.

\section{Description of Proposed System:}

- Hardware - In-tank Rotary Micro-Filters (RMF), two (lead/lag) Small Column Ion Exchange (SCIX) columns using SRF resin, elution equipment, and supporting pumps/equipment

- Supernate/Saltcake Process Flow

- Filter with RMF and discharge filtered solids back into the tank

- Process filtered permeate through SCIX columns to remove Cesium (Cs)

- Elute sRF resin to remove Cs; regenerate resin for further use

- Discharge neutralized eluate to DST.

- Cs-rich eluate may be transferred directly to the WTP when it becomes available.

- Spent sRF beads may be disposed as low-level waste. They may also potentially be processed through the FBSR. This is also a potential disposition path for SRF resin used as part of WTP pretreatment.

- Feed clarified salt solution from SCIX to FBSR to produce a monolithic mineralized product.

- Dispose of monolithic mineralized product to IDF. 


\section{Reasons for Selection of SRF at Hanford as the Ion Exchange Resin:}

- Spherical resorcinol formaldehyde (sRF) is the baseline ion exchange resin for the WTP pretreatment facility. Substantial sRF waste testing with actual and simulated Hanford waste for WTP has been conducted.

- The lower Cs content of Hanford waste would require CST resin to be in service up to ten times longer than it will be at SRS, presenting a risk of agglomeration of the resin bed (e.g., 70 days at $10 \mathrm{gpm}, 140$ days at $5 \mathrm{gpm}$ ).

- Agglomeration behavior has not been observed for sRF resin. As Hanford wastes are chemically more varied and complex than SRS wastes (as a result of multiple flowsheet processes during weapons material production) there would be more potential mechanisms to cause agglomeration behavior. In the event CST was used, Hanford-specific agglomeration testing would be required.

- sRF will not increase the amount of HLW sludge to be vitrified. Conversely, the use of CST would increase the volume of HLW sludge to be vitrified by up to $6 \%$ as a result of sending the ground CST resin to the WTP facility.

- All Hanford wastes, both HLW and LAW, are subjected to caustic leaching and elevated temperatures $\left(5 \mathrm{M} \mathrm{NaOH}\right.$ at $\left.85^{\circ} \mathrm{C}\right)$ as part of the process to separate $\mathrm{Al}$ and $\mathrm{Cr}$ from the HLW fraction. In the event CST was used for supplemental treatment, partial dissolution of ground CST in the WTP caustic leaching step might lead to $<0.1 \mu$ complexed $\mathrm{Cs}$ that would pass through the WTP filtration and ion exchange (sRF) pretreatment, defeating cesium decontamination. Though this scenario is unlikely, the accompanying risk is so high that it would require investigation (with the accompanying time and expense) to ensure it would not be an issue.

- Hanford will initially have no processing path (HLW vitrification facility) for ground CST, requiring significant accumulation and extended in-tank storage of the ground CST until a processing path is available. The accumulation and extended in-tank storage of ground, Cs-loaded CST resin presents additional tank mixing requirements and potential for blockage of the 2-mile inter-area transfer line.

\section{Open Technical Issues}

- Design input studies:

- Evaluate processing of spent $\mathrm{sRF}$ resin through an FBSR as an alternative to sluicing the spent resin to a high integrity container (HIC).

- Optimize elution and regeneration frequencies.

- Determine disposition/neutralization pathway for elution chemicals.

- Evaluate loaded $\mathrm{sRF}$ resin and $\mathrm{sRF}$ resin eluant $\mathrm{H}_{2}$ generation rates for the tank and downstream processes. 
RPP-47630, Rev. 0

\section{APPENDIX B - SAVANNAH RIVER SITE SPECIFIC INFORMATION REGARDING ION EXCHANGE MEDIA SELECTION}

(document prepared during April 2010 meeting at SRS) 


\section{MODULAR SALT PROCESSING (MSP) MISSION NEEDS}

- Enables lifecycle improvement of SRS liquid waste system

- Eliminates salt-only campaign at Defense Waste Processing Facility (DWPF)

- Accelerates supernate and saltcake salt processing

- Reduces lifecycle by 6 years

- Saves \$3.6 Billion (assume start-up in 12/2013)

- Mitigates risk of potential delay or performance penalty in the SWPF

- Helps ensure compliance with the SRS Site Treatment Plan to process all high-level waste by 2028 (System Plan R15 indicates completion by 2030 without MSP)

\section{SRS Liquid Waste System Enablers:}

- DWPF - Batch removed Sr, actinides and Cs-loaded CST resin with sludge from other tanks as feed to DWPF for vitrification and disposal at an off-site repository

- Salt Production Facility (SPF) and SDF - Batch decontaminated salt solution (DSS) with other low-level salt wastes (H-canyon \& Effluent Treatment Facility, ARP/ MCU or SWPF) for processing by the SPF for disposal at SDF

\section{Description of Proposed System:}

- Hardware - In-tank Rotary Micro-Filters (RMF), two (lead/lag) Small Column Ion Exchange (SCIX) columns using Crystalline Silicotitanate (CST) resin, in-tank grinder, and supporting pumps/equipment

- Process Flow

- Perform in-tank Monosodium Titanate (MST) strike to precipitate Strontium (Sr) and actinides

- Filter out Sr and actinide precipitates by RMF and drop back into the tank

- Process clarified salt solution through SCIX columns to remove Cesium (Cs)

- Ground loaded CST resin to micron-size particles

- Mix the Sr and actinide precipitate and the ground Cs loaded CST resin with sludge and transfer as feed to DWPF

- Send DSS to SPF for disposal at SDF. 


\section{Reasons for Selection of CST Resin:}

- Substantial SRS actual and stimulant waste testing with CST, testing with sRF on-going

- CST currently being used at Oak Ridge National Laboratory to treat liquid wastes

- Titanium impact on number of DWPF canisters judged to be acceptable

- Significant modifications of DWPF (cost and downtime) required to process nitric acid used to elute the sRF resin; technology studies to use non-acid elution for $\mathrm{sRF}$ are still on-going

- $\mathrm{Hg}$ in SRS tank wastes create resin disposal uncertainty

- Although sRF has desirable attributes should it be successfully matured for SRS specific waste, deferred deployment (to perform SRS specific waste testing) will significantly reduce the lifecycle and cost improvements

- Formal system engineering evaluation confirmed selection of CST (G-ADS-H-00014, $12 / 18 / 2008)$

Open Technical Issues (Examination of Small Column Ion Exchange CD-0 to CD-1, Memo from Thomas Huff to Cliff Winkler, SRR-LWE-2009-00078, 10/15/09):

- Design input studies:

- Sluicing method for spent CST resin from the IX column to a grinder and ground CST resin from a grinder to another tank have not been demonstrated

- Settling behavior of ground CST resin and impact on sludge washing need to be determined

- Testing of bearing and seals for RMF for endurance

- Determining impact on MAR, criticality and shielding requirement of CST loading

- Evaluating loaded CST resin $\mathrm{H}_{2}$ generation rates for the tank and downstream processes (sludge batch preparation and DWPF)

- System effect studies:

- Evaluating CST impacts to glass formulation - titanium and niobium

- Determining MST settling and re-suspension in large tanks, and at elevated temperature and extended settling time

- Determining maximum fissile loading for MST for criticality controls 
RPP-47630, Rev. 0

\section{APPENDIX C - TECHNICAL DATASHEETS FOR DYNOSEEDS ${ }^{\circledR}$ RF 380 AND} IONSIV ${ }^{\circledR}$ IE-911 


\section{Technical Data Sheet Dynoseeds $^{\circledR}$ RF 380}

Particles for purification of radioactive waste.

\section{Special features}

Monosized particles

- Solid resorcinol formaldehyde particles

- Ion exchange resin

- Binding of ${ }^{137} \mathrm{Cs}$ isotope

- Homogenous particle surface

- Very good chemical properties

- Very good hydraulic properties

\section{Properties}

Solid monosized resorcinol formaldehyde particles for removal of the radioactive isotope ${ }^{137} \mathrm{Cs}$ from radioactive waste has been developed in cooperation with Bechtel Inc. and Department of Energy in the US. Monosized resorcinol formaldehyde particles produced by Microbeads have shown to exhibit no measurable degradation in $\mathrm{Cs}$ removal performance by cycling and oxidation do not degrade the resin either chemically or hydraulically.

\section{Superior hydraulic \& chemical properties} $\downarrow$

Durability gives cost savings
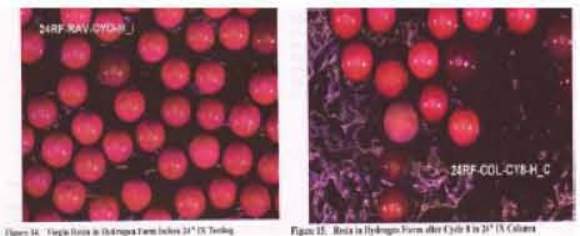

\section{Typical applications}

Monosized resorcinol formaldehyde has a high selectivity and capacity for binding ${ }^{137} \mathrm{CS}$ and can therefore be used to remove the radioactive isotope ${ }^{137} \mathrm{Cs}$ from aqueous alkaline solutions by ion exchange. Large ion exchange columns are filled with resorcinol formaldehyde particles and the radioactive waste is purified by passing through the columns. This product will be used in the purification of the radioactive waste at the large waste treatment plant, WTP at Hanford site, the Washington state USA.
Tel: +4764835300

Fax: +4764835301

June 102009

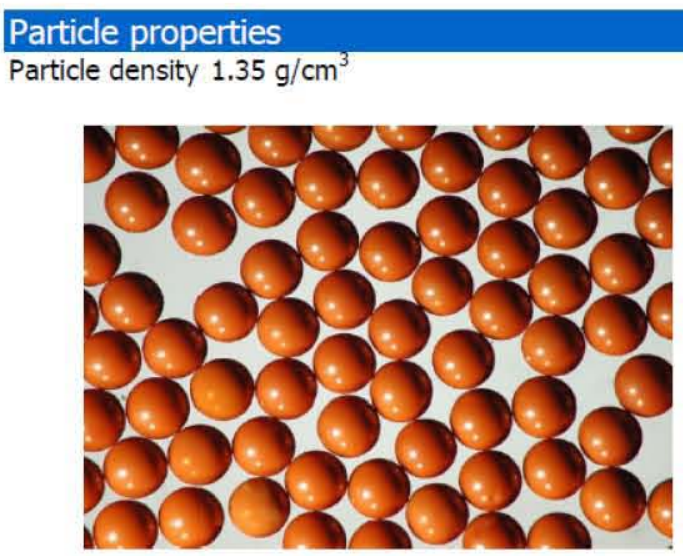

Technical data

\begin{tabular}{|l|c|c|}
\hline Dynoseeds $^{\circledR}$ & $\mathrm{D}_{\text {mean }}[\mu \mathrm{m}]$ & $\mathrm{CV}[\%]$ \\
\hline RF 380 & 380 & $<5$ \\
\hline
\end{tabular}

Particle size distribution by Coulter Multisizer 3:

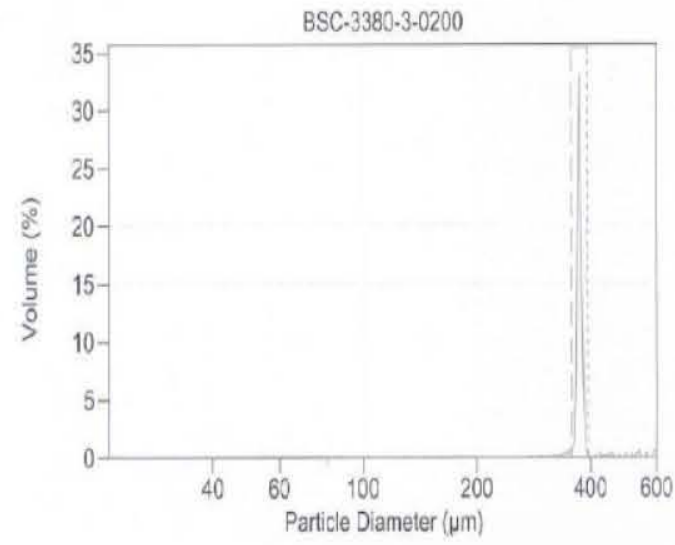

http://micro-beads.com/UserFiles/file/pdf 2009/Technical\%20Datasheet $\% 20 \mathrm{RF} \% 202009 \% 2006 \% 2010$.pdf 


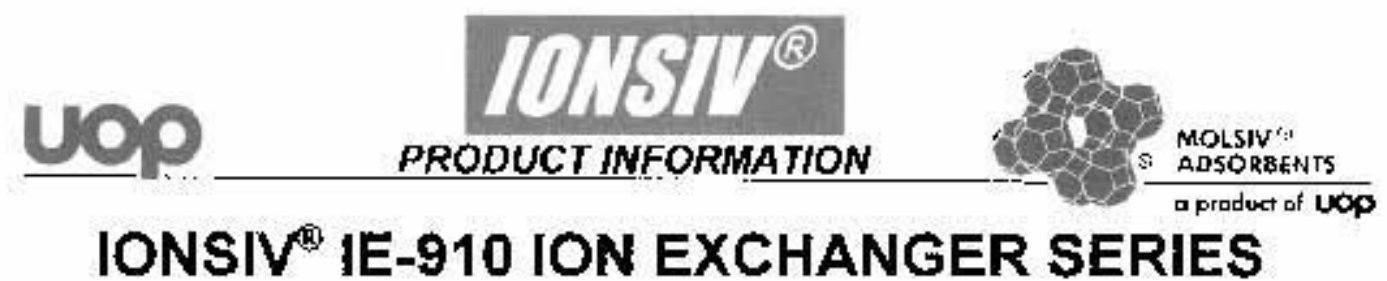

Ihesciptisms

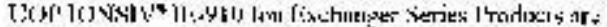

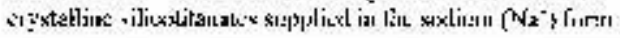

Chemisal Formita

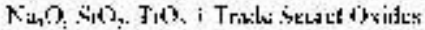

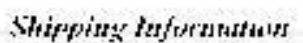

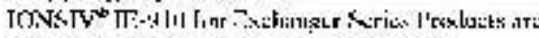

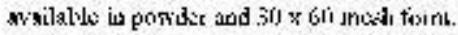

Noinstiminn

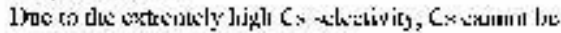

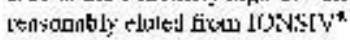

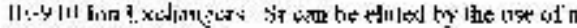
striealilus ade solutickt.

Ty:rricut spplicatiess - Ircts:

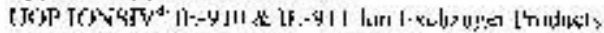

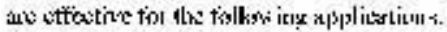

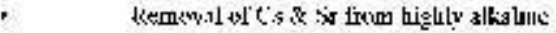

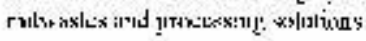

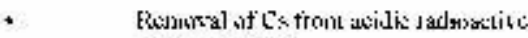
Hillsk: $50: v \mid$ lung:

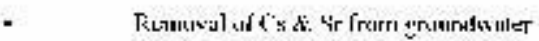

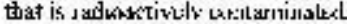

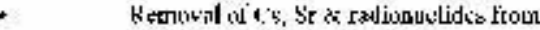

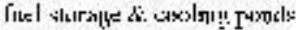

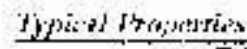

\begin{tabular}{|c|c|c|}
\hline & TA & II ब्या। \\
\hline 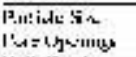 & 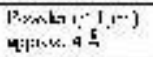 & 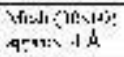 \\
\hline 1 & & 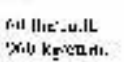 \\
\hline 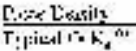 & & 2.+口, wl \\
\hline
\end{tabular}

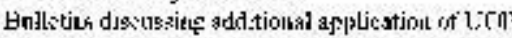

Hitede:

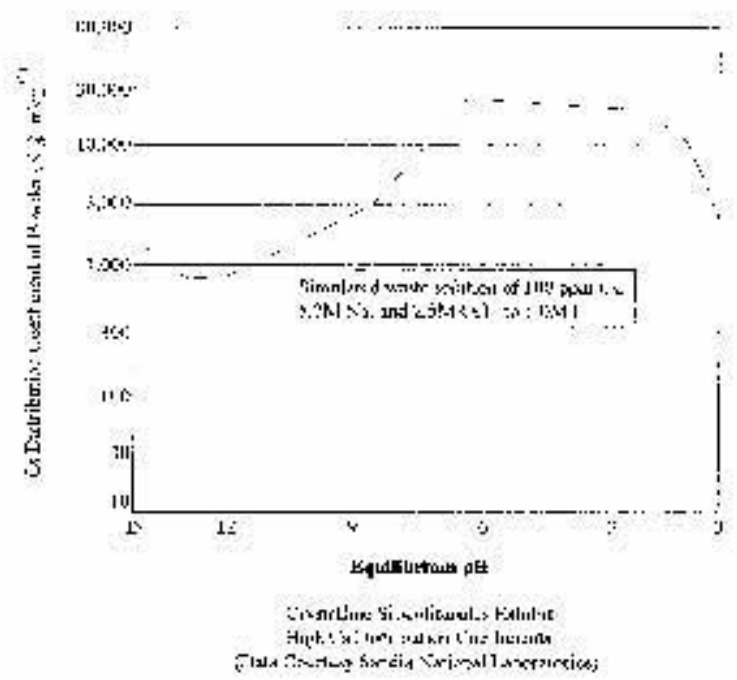

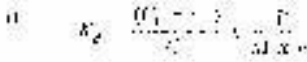

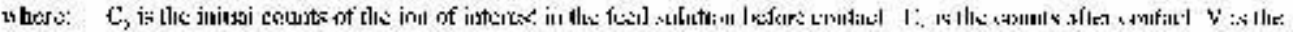

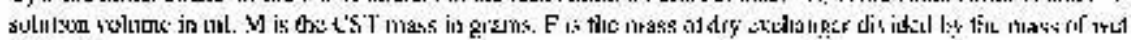

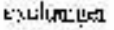

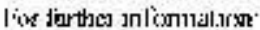

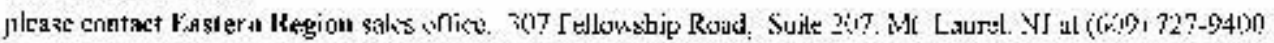

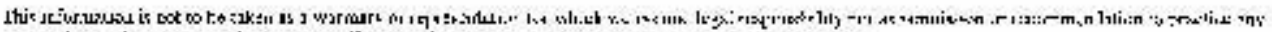

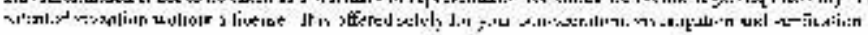

$$
\therefore ?^{*}
$$

